Cochrane Database of Systematic Reviews

\title{
Early planned removal of umbilical venous catheters to prevent infection in newborn infants (Review)
}

Gordon A, Greenhalgh M, McGuire W

Gordon A, Greenhalgh M, McGuire W.

Early planned removal of umbilical venous catheters to prevent infection in newborn infants.

Cochrane Database of Systematic Reviews 2017, Issue 10. Art. No.: CD012142.

DOI: 10.1002/14651858.CD012142.pub2.

www.cochranelibrary.com 
TABLE OF CONTENTS

HEADER 1

ABSTRACT

PLAIN LANGUAGE SUMMARY ....

SUMMARY OF FINDINGS

BACKGROUND

OBJECTIVES

METHODS

RESULTS

Figure 1.

Figure 2.

Figure 3.

Figure 4.

Figure 5.

Figure 6.

Figure 7.

DISCUSSION

AUTHORS' CONCLUSIONS

ACKNOWLEDGEMENTS

REFERENCES

CHARACTERISTICS OF STUDIES

DATA AND ANALYSES

Analysis 1.1. Comparison 1 Early planned UVC removal vs later planned removal or expectant management, Outcome 1 Bloodstream infection.

Analysis 1.2. Comparison 1 Early planned UVC removal vs later planned removal or expectant management, Outcome 2 Bloodstream infection by micro-organism.

Analysis 1.3. Comparison 1 Early planned UVC removal vs later planned removal or expectant management, Outcome 3 Allcause mortality.

Analysis 1.4. Comparison 1 Early planned UVC removal vs later planned removal or expectant management, Outcome 4 Pericardial effusion.

Analysis 1.5. Comparison 1 Early planned UVC removal vs later planned removal or expectant management, Outcome 5 Catheter-associated thrombosis necessitating removal of catheter.

Analysis 1.6. Comparison 1 Early planned UVC removal vs later planned removal or expectant management, Outcome 6 Number of cannulas or catheters used per infant.

Analysis 1.7. Comparison 1 Early planned UVC removal vs later planned removal or expectant management, Outcome 7 Necrotising enterocolitis (Bell stage 2 or 3 ).

APPENDICES

CONTRIBUTIONS OF AUTHORS

DECLARATIONS OF INTEREST

SOURCES OF SUPPORT

DIFFERENCES BETWEEN PROTOCOL AND REVIEW

INDEX TERMS 
[Intervention Review]

\section{Early planned removal of umbilical venous catheters to prevent infection in newborn infants}

Adrienne Gordon ${ }^{1}$, Mark Greenhalgh², William McGuire ${ }^{3}$

1Neonatology, Royal Prince Alfred Hospital, Sydney, Australia. 2RPA Newborn Care, RPA Women and Babies, Royal Prince Alfred Hospital, Sydney, Australia. ${ }^{3}$ Centre for Reviews and Dissemination, The University of York, York, UK

Contact address: William McGuire, Centre for Reviews and Dissemination, The University of York, York, Y010 5DD, UK. William.McGuire@hyms.ac.uk.

Editorial group: Cochrane Neonatal Group.

Publication status and date: New, published in Issue 10, 2017.

Citation: Gordon A, Greenhalgh M, McGuire W. Early planned removal of umbilical venous catheters to prevent infection in newborn infants. Cochrane Database of Systematic Reviews 2017, Issue 10. Art. No.: CD012142. DOI: 10.1002/14651858.CD012142.pub2.

Copyright @ 2017 The Cochrane Collaboration. Published by John Wiley \& Sons, Ltd.

\section{A B S T R A C T}

\section{Background}

Lengthy duration of use may be a risk factor for umbilical venous catheter-associated bloodstream infection in newborn infants. Early planned removal of umbilical venous catheters (UVCs) is recommended to reduce the incidence of infection and associated morbidity and mortality.

\section{Objectives}

To compare the effectiveness of early planned removal of UVCs (up to two weeks after insertion) versus an expectant approach or a longer fixed duration in preventing bloodstream infection and other complications in newborn infants.

To perform subgroup analyses by gestational age at birth and prespecified planned duration of UVC placement (see "Subgroup analysis and investigation of heterogeneity").

\section{Search methods}

We used the standard Cochrane Neonatal search strategy including electronic searches of the Cochrane Central Register of Controlled Trials (CENTRAL; 2017, Issue 4), Ovid MEDLINE, Embase, and the Maternity \& Infant Care Database (until May 2017), as well as conference proceedings and previous reviews.

\section{Selection criteria}

Randomised and quasi-randomised controlled trials that compared effects of early planned removal of UVCS (up to two weeks after insertion) versus an expectant approach or a longer fixed duration in preventing bloodstream infection and other complications in newborn infants.

\section{Data collection and analysis}

Two review authors assessed trial eligibility and risk of bias and independently undertook data extraction. We analysed treatment effects and reported risk ratio (RR) and risk difference (RD) for dichotomous data, and mean difference (MD) for continuous data, with respective 95\% confidence intervals (Cls). We planned to use a fixed-effect model in meta-analyses and to explore potential causes of heterogeneity in sensitivity analyses. We assessed the quality of evidence for the main comparison at the outcome level using GRADE methods. 


\section{Main results}

We found one eligible trial. Participants were 210 newborn infants with birth weight less than 1251 grams. The trial was unblinded but otherwise of good methodological quality. This trial compared removal of an umbilical venous catheter within 10 days after insertion (and replacement with a peripheral cannula or a percutaneously inserted central catheter as required) versus expectant management (UVC in place up to 28 days). More infants in the early planned removal group than in the expectant management group (83 vs 33 ) required percutaneous insertion of a central catheter (PICC). Trial results showed no difference in the incidence of catheter-related bloodstream infection (RR $0.65,95 \% \mathrm{Cl} 0.35$ to 1.22 ), in hospital mortality (RR 1.12, 95\% Cl 0.42 to 2.98 ), in catheter-associated thrombus necessitating removal (RR 0.33 , 95\% confidence interval 0.01 to 7.94 ), or in other morbidity. GRADE assessment indicated that the quality of evidence was "low" at outcome level principally as the result of imprecision and risk of surveillance bias due to lack of blinding in the included trial.

\section{Authors' conclusions}

Currently available trial data are insufficient to show whether early planned removal of umbilical venous catheters reduces risk of infection, mortality, or other morbidity in newborn infants. A large, simple, and pragmatic randomised controlled trial is needed to resolve this ongoing uncertainty.

\section{PLAIN LANGUAGE SUMMARY}

\section{Early planned removal of umbilical venous catheters to prevent infection in newborn infants}

\section{Review question}

In newborn infants with an umbilical venous catheter, how does planned removal within two weeks after insertion compare with an expectant approach or a longer fixed duration in preventing bloodstream infection and other complications?

\section{Background}

Preterm and sick term newborn babies may require an umbilical venous catheter (UVC) - a fine plastic tube that is inserted via the infant's umbilical vein (in the tummy button) several centimetres into the infant's major blood vessel to deliver nutrition and drugs. Infection in the bloodstream is a frequent and harmful complication for newborn infants who have a UVC in place. One method that may be used to reduce the risk of this and other serious complications is removal of the UVC within about two weeks after insertion (rather than leaving it until no longer required) and replacement with a cannula or a catheter inserted via a small vein (usually in the arm or leg).

\section{Study characteristics}

We found only one small randomised controlled trial (including 210 very low birth weight newborn infants) that addressed this question.

\section{Key results}

This trial did not show that early planned removal of UVCs from infants could reduce their chance of developing a bloodstream infection. However, because the trial was small, this finding is not certain.

\section{Conclusions}

The trial did not provide sufficient evidence to inform policy or practice; larger trials are needed to resolve this question fully. 


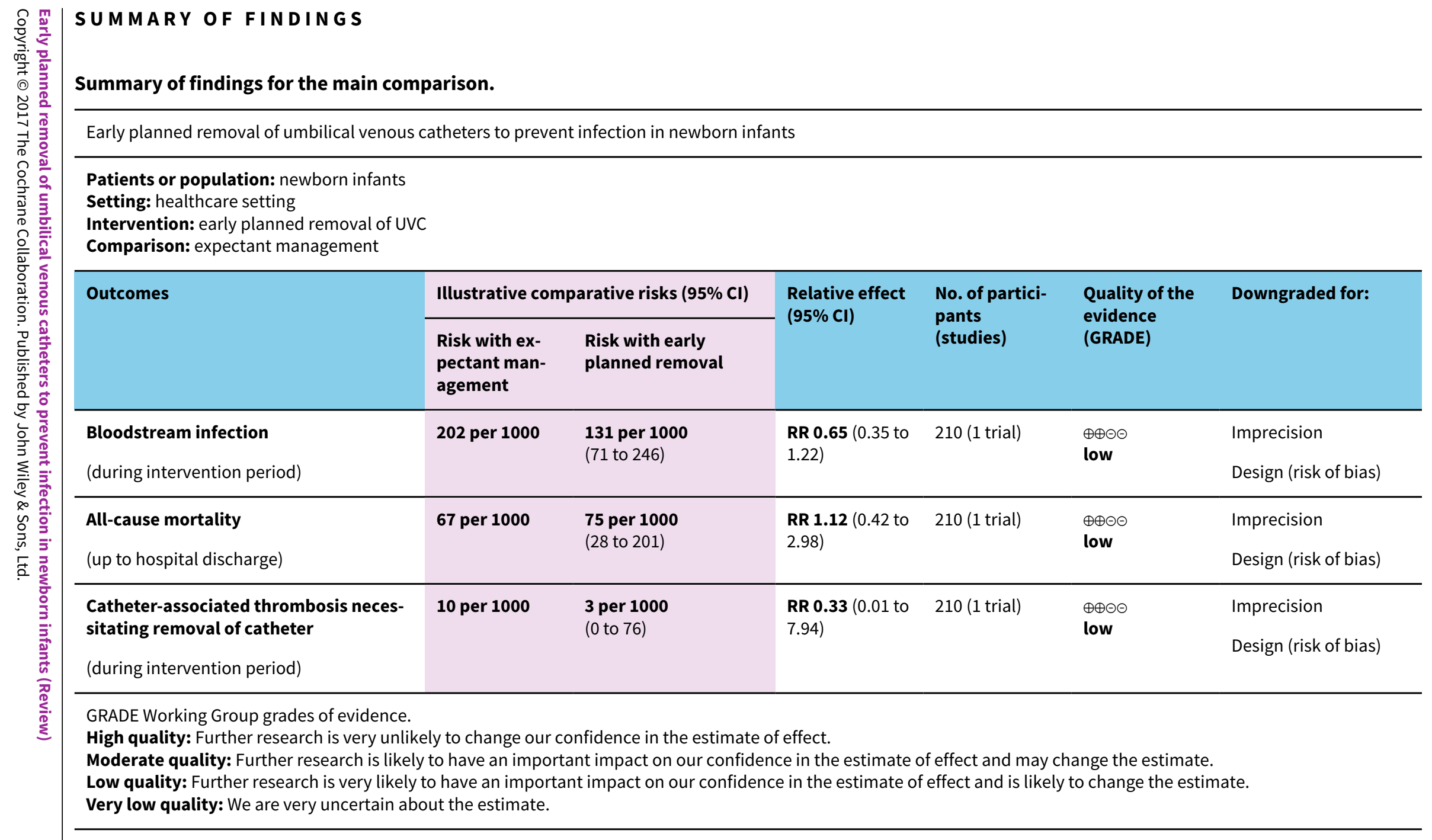

$\mathrm{Cl}$ : confidence interval.

RR: risk ratio. 


\section{B A C K G R O U N D}

\section{Description of the condition}

Umbilical venous catheters (UVCs) are used to establish a secure central vascular route for delivery of drugs or fluids to preterm or sick newborn infants. UVCs are usually inserted within the first few days after birth, when the umbilical cord stump can be manipulated and the opening of the umbilical vein is patent and easily visualised (Seguin 1994; Green 1998; Nash 2006). Evidence suggests that use of UVCs rather than short peripheral venous cannulas facilitates consistent delivery of parenteral nutrients to preterm infants and reduces the number of venipunctures that infants must undergo (Pereira 1992). Because UVCs terminate within large central vessels rather than small, fragile peripheral vessels, their use may reduce the risk of subcutaneous extravasation injury caused by hyperosmolar solutions and medications (Hermansen 2005).

As with other types of central vascular catheters (CVCs), use of UVCs is associated with complications that may cause morbidity and mortality (Wu 2012). Bloodstream infection is the most common serious adverse event, with reported incidence ranging from $3 \%$ to more than $20 \%$, depending on the precise diagnostic criteria applied and the demographics of the population studied (O'Grady 2011; Schulman 2011; Butler-O'Hara 2012). Newborn infants, particularly very preterm infants, with acquired bloodstream infection are at higher risk for mortality and for a range of important morbidities including bronchopulmonary dysplasia, necrotising enterocolitis, retinopathy of prematurity, and prolonged hospitalisation (Saint 2000; Chapman 2003; Payne 2004; Adams-Chapman 2006; Hermans 2007; Lahra 2009). Bloodstream infection is associated with higher rates of adverse neurodevelopmental outcomes including cognitive or sensory impairment and cerebral palsy (Stoll 2004; Shah 2008; Bassler 2009). Other potentially serious complications of UVC use include thrombosis formation in the catheter lumen or tip and thromboembolism, arrhythmias triggered by a UVC tip positioned within the cardiac chambers, and malposition or migration of the UVC tip within peritoneal, pleural. or pericardial spaces (which can cause ascites, pleural effusion, or cardiac tamponade), or within the portal venous system (which may result in hepatic necrosis and long-term liver dysfunction) (Panetta 2000; Kim 2001; Traen 2005; Shareena 2008; Narang 2009; Arnts 2014; Grizelj 2014; Hollingsworth 2015; Mutlu 2016).

\section{Description of the intervention}

Uncertainty surrounds the effects of duration of placement ('dwell time') on risk of UVC-associated bloodstream infections and other complications in newborn infants. Observational studies estimate that risk of infection increases with dwell times longer than about 7 to 14 days (Seguin 1994; Zingg 2011; Butler-O'Hara 2012). It is not certain, however, to what extent UVC use is an independent risk factor for a bloodstream infection, or whether observed associations exist because infants who are smaller, less mature, and sicker who are receiving more intensive and invasive support are more likely to have a UVC in place longer (Shahid 2014).

The US Centers for Disease Control and Prevention (CDC) Hospital Infection Control Practices Advisory Committee currently recommends that UVCs should be removed as soon as possible when no longer needed but can be used for up to 14 days if managed aseptically (O'Grady 2011). Consistent with these recommendations, standard clinical practice in many neonatal units is to remove UVCs before 14 days (often by 7 days). Replacement intravenous access, if required, can be attained via short peripheral cannulas, or via percutaneously inserted central catheters (PICCS) if ongoing central access is needed (Wu 2012; Taylor 2014). It is unclear, however, whether or how this strategy of serial central line use affects rates of bloodstream infection and other catheter-related complications (Keir 2014).

\section{How the intervention might work}

Prespecifying a fixed maximum dwell time with planned removal rather than an expectant approach may reduce the risk that a UVC may be left in place when not in use or needed. This could lower the risk of bloodstream infection and its associated complications if the UVC is an independent risk factor for bloodstream infection. This intervention may plausibly affect nutrient intake, reducing receipt of parenteral nutrients or prompting a more rapid progression to full enteral feeding, or both, with potential consequences for acute morbidity (principally risk of acute necrotising enterocolitis), growth, and development.

\section{Why it is important to do this review}

Given the fact that for the planned duration of UVC, placement may affect important outcomes for newborn infants, we undertook a systematic review to identify, appraise, and synthesise available evidence from randomised controlled trials.

\section{Related Cochrane Reviews}

Other Cochrane Reviews have assessed effects of strategies including antimicrobial impregnation or antibiotic locks in preventing UVC- and other CVC-related infection in newborn infants, and early removal versus expectant management of PICC in infants with suspected bloodstream infection (Balain 2015; Taylor 2015). Another review evaluated evidence for use of short-term versus longer-term PICC in newborn infants (Gordon 2016).

\section{O B J E C T IVES}

To compare the effectiveness of early planned removal of umbilical venous catheters (UVCS) (up to two weeks after insertion) versus an expectant approach or a longer fixed duration in preventing bloodstream infection and other complications in newborn infants.

To perform subgroup analyses by gestational age at birth and prespecified planned duration of UVC placement (see Subgroup analysis and investigation of heterogeneity).

\section{METHODS}

\section{Criteria for considering studies for this review}

\section{Types of studies}

Randomised and quasi-randomised controlled trials, including cluster-randomised controlled trials.

\section{Types of participants}

Newborn infants requiring a UVC for central vascular access. 


\section{Types of interventions}

- Intervention: prespecified planned UVC removal at any day up to 14 days after insertion

- Control: permissible duration of placement that is at least seven days longer than specified for the intervention group, or a permissive approach that does not prespecify dwell time but allows for removal on clinical grounds (including suspected or confirmed bloodstream infection), or when the UVC is no longer required

Trials that assessed the effects of a prespecified intended duration of UVC placement as part of a package of infection control measures (care bundle) were eligible for inclusion, but we planned to analyse these separately from trials of discrete interventions.

\section{Types of outcome measures}

\section{Primary outcomes}

- Incidence of bloodstream infection confirmed by culture of blood sampled from peripheral sites (not from indwelling catheters) during hospital admission. When data were available, we excluded cases in which infection was attributed to diphtheroids, micrococci, Propionibacteriaceae, or mixed microbial flora. When sufficient data were available, we examined the effect on infection with:

* coagulase-negative staphylococci;

* other bacteria (Gram-negative bacilli, Staphylococcus aureus, enterococci); or

* fungi.

\section{Secondary outcomes}

- Neonatal mortality (<28 days) and death due to all causes before hospital discharge and up to one year post term

- Neurodevelopmental outcomes assessed after 12 months post term using validated tools: neurological evaluations; developmental scores; and classifications of disability, including auditory and visual disability. We defined neurodevelopmental impairment as the presence of one or more of the following: non-ambulant cerebral palsy; developmental quotient more than two standard deviations below the population mean; and blindness (visual acuity $<6 / 60$ ) or deafness (any hearing impairment requiring or unimproved by amplification)

- Death or neurological impairment assessed after 12 months post term

- Growth: time (days) to regain birth weight and average rates of weight gain (grams $/ \mathrm{kg} / \mathrm{d})$, linear growth $(\mathrm{mm} /$ week), head growth (mm/week) and skinfold thickness growth (mm/week) during hospital admission

- Extravasation injury: subcutaneous extravasation resulting in skin ulceration; 'deep' extravasation resulting in limb swelling; or 'central' extravasation-infusate in the pleural, peritoneal, or pericardial space

- Number of cannulas or catheters used per infant to administer parenteral fluids until full enteral feeding was established

- Days to full enteral feeding

- Central catheter leak, obstruction, or breakage necessitating removal of the catheter

- Catheter-associated thrombosis necessitating removal of the catheter
- Other morbidity developing after enrolment in the trial until discharge from the hospital

* Bronchopulmonary dysplasia (oxygen supplementation at 36 weeks' postmenstrual age) (Ehrenkranz 2005)

* Necrotising enterocolitis (Bell stage 2 or 3) (Walsh 1986)

* Retinopathy of prematurity requiring treatment (medical or surgical) (ICROP 2005)

\section{Search methods for identification of studies}

See the Cochrane Neonatal Review Group search strategy (http:// neonatal.cochrane.org/).

\section{Electronic searches}

We searched the Cochrane Central Register of Controlled Trials (CENTRAL; 2017, issue 5), Ovid MEDLINE (1946 to May 2017), OVID Embase (1974 to May 2017), OVID Maternity \& Infant Care Database (1971 to May 2017), and the Cumulative Index to Nursing and Allied Health Literature (CINAHL; 1982 to May 2017) using a combination of the text words and MeSH terms presented in Appendix 1 . We limited search outputs by using relevant search filters for clinical trials as recommended in the Cochrane Handbook for Systematic Reviews of Interventions (Higgins 2011). We did not apply language restrictions.

We searched ClinicalTrials.gov and the International Trials Registry Platform of the World Health Organization (www.whoint/ictrp/ search/en/) for completed and ongoing trials.

\section{Searching other resources}

We examined reference lists in previous reviews and included studies. We searched the proceedings of annual meetings of the Pediatric Academic Societies (1993 to 2017), the European Society for Pediatric Research (1995 to 2016), the Royal College of Paediatrics and Child Health (2000 to 2017), and the Perinatal Society of Australia and New Zealand (2000 to 2016). Trials reported only as abstracts were eligible if sufficient information was available from the report, or from contact with trial authors, to fulfil the inclusion criteria.

\section{Data collection and analysis}

We used the standard methods of Cochrane Neonatal.

\section{Selection of studies}

We screened the title and abstract of all studies identified by the above search strategy, and two review authors independently assessed the full articles for all potentially relevant trials. We excluded studies that do not meet all of the inclusion criteria. We discussed disagreements until we achieved consensus.

\section{Data extraction and management}

Two review authors (MG and WM) extracted data independently using a data collection form to collect from each included study information on design, methods, participants, interventions, outcomes, and treatment effects. We discussed disagreements until we reached a consensus. If data from trial reports were insufficient, we contacted trialists to request further information. 


\section{Assessment of risk of bias in included studies}

We used the criteria and standard methods of Cochrane Neonatal to assess the methodological quality of included trials. Two review authors assessed risk of bias across key domains and resolved disagreements in consultation with a third review author (Appendix 2). We planned to request additional information from trial authors to clarify methods and results when necessary. We did not exclude trials on the basis of risk of bias, but we did plan to conduct sensitivity analyses if applicable to explore the consequences of synthesising evidence of variable quality (Higgins 2011)

\section{Measures of treatment effect}

We analysed treatment effects in individual trials using RevMan 2014 and reported risk ratio (RR) and risk difference (RD) for dichotomous data, and mean difference (MD) for continuous data, with respective $95 \%$ confidence intervals $(\mathrm{Cls})$. We determined the number needed to treat for an additional beneficial outcome (NNTB) or an additional harmful outcome (NNTH) for analyses with a statistically significant difference in RD.

\section{Unit of analysis issues}

The unit of analysis was the participating infant in individually randomised trials, and the neonatal unit (or sub-unit) in clusterrandomised trials.

An infant was to be considered only once in an analysis. We planned to exclude infants with multiple enrolments, as we would not be able to address the unit of analysis issues that might arise.

For cluster-randomised trials, we planned to undertake analyses at the level of the individual while accounting for clustering of data using the methods recommended in the Cochrane Handbook for Systematic Reviews of Interventions (Higgins 2011).

\section{Dealing with missing data}

When data were missing and could not be derived as described, we planned to approach the analysis as follows.

- Contact original study investigators to request missing data.

- When possible, impute missing standard deviations (SDs) using the coefficient of variation (CV), or calculate from other available statistics including standard errors, confidence intervals, $t$ values, and $P$ values.

- If data were assumed to be missing at random, analyse the data without imputing missing values.

- If this could not be assumed, impute missing outcomes with replacement values, assuming all to have a poor outcome.

We planned to conduct sensitivity analyses to assess changes in the direction or magnitude of effect resulting from data imputation.

\section{Assessment of heterogeneity}

Two review authors (WM and MG) planned to assess clinical heterogeneity, and undertook a meta-analysis only when both review authors agreed that study participants, interventions, and outcomes were sufficiently similar. We planned to assess statistical heterogeneity through visual inspection of forest plots. We planned to calculate the $\mathrm{I}^{2}$ statistic for each RR analysis to quantify inconsistency across studies and to describe the percentage of variability in effect estimates that may be due to heterogeneity rather than to sampling error. If we detected 'high' levels of heterogeneity $\left(I^{2} \geq 75 \%\right)$, we planned to explore possible causes (e.g. differences in study design, participants, interventions, completeness of outcome assessments).

\section{Assessment of reporting biases}

We planned to assess publication bias through visual inspection of funnel plot asymmetry in meta-analyses consisting of at least 10 trials.

\section{Data synthesis}

We planned to use the fixed-effect model in Review Manager 5.3 for meta-analyses (as per Cochrane Neonatal recommendations).

\section{Quality of evidence}

We assessed the quality of evidence for main comparisons at the primary outcomes level using the GRADE approach, as outlined in the GRADE Handbook (Guyatt 2011a; Schünemann 2013). Two review authors independently assessed the quality of the evidence for outcomes identified as critical or important for clinical decision making (i.e. infection, death, and thrombosis). We considered evidence from randomised controlled trials as high quality but downgraded the evidence one level for serious (or two levels for very serious) limitations based upon the following: design (risk of bias), consistency across studies, directness of evidence, precision of estimates, and presence of publication bias (Appendix 3). We used GRADEproGDT to create a 'Summary of findings' table to report the quality of the evidence (GRADEproGDT).

\section{Subgroup analysis and investigation of heterogeneity}

If we identify sufficient studies, we planned to undertake these subgroup analyses.

- Very preterm (<32 weeks) infants (vs infants born at $\geq 32$ weeks).

- Prespecified planned duration of UVC placement up to 7 days (vs longer durations up to 14 days).

\section{Sensitivity analysis}

We planned to undertake sensitivity analyses to determine whether findings were affected by including only studies using adequate methods (low risk of bias), defined as adequate randomisation and allocation concealment, blinding of intervention, and measurement, with $<10 \%$ loss to follow-up.

\section{RES U L T S}

\section{Description of studies}

\section{Results of the search}

We included one trial and excluded seven reports (Figure 1. 
Figure 1. Study flow diagram.

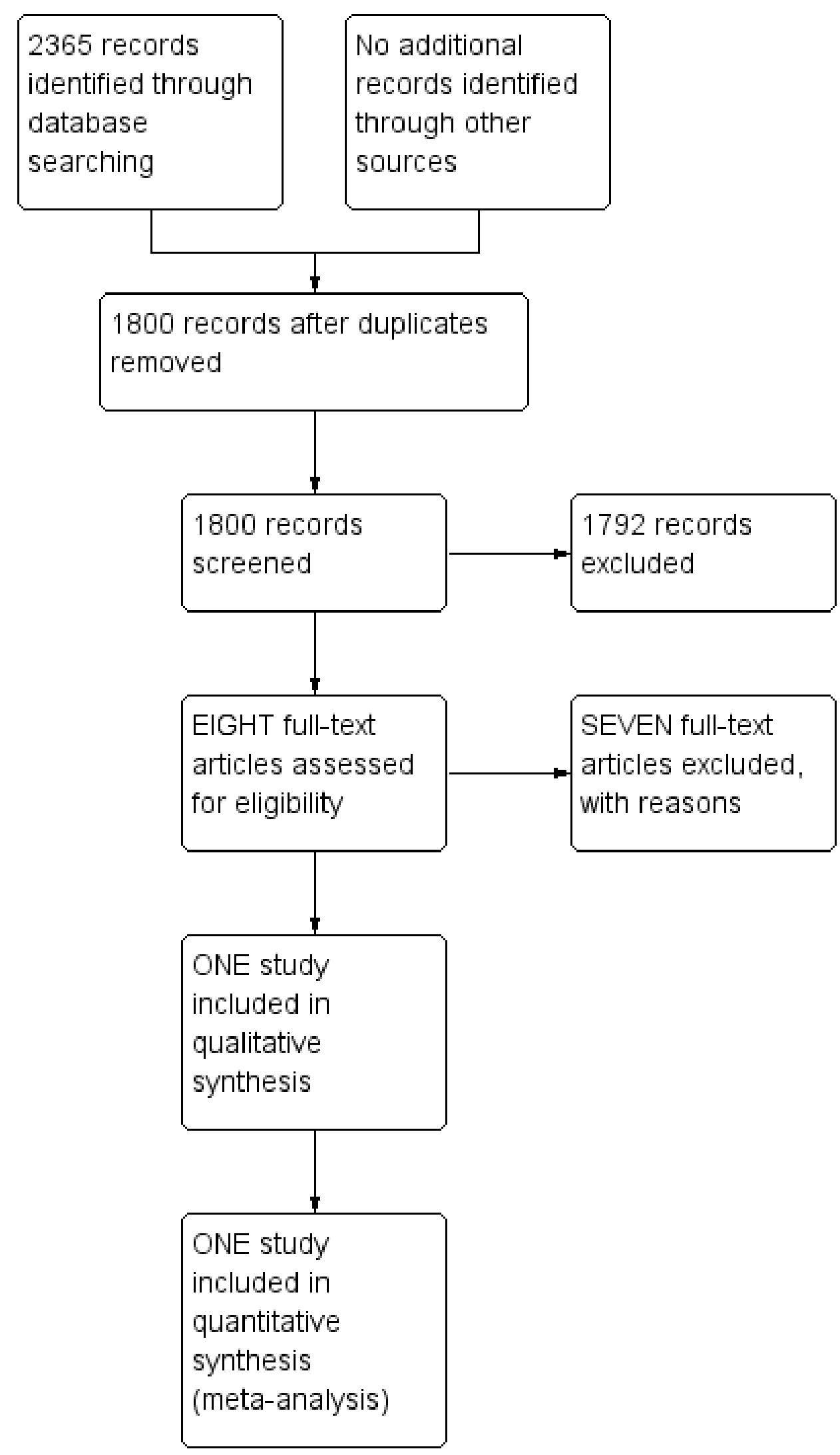




\section{Included studies}

We included one trial, which was conducted between 1998 and 2004 at a tertiary referral neonatal unit in the USA (Butler O'Hara 2006; Characteristics of included studies). Infants of birth weight less than 1251 grams who had a double-lumen UVC placed upon admission to the neonatal unit were eligible for participation in the study. Trialists excluded infants who required a UVC for exchange transfusion, infants with gastrointestinal abnormalities, and infants with congenital heart disease.

For infants in the intervention (early planned removal) arm ( $\mathrm{N}=$ 106), the UVC remained in place for up to 7 to 10 days. If ongoing central access was required, a PICC was placed by day 10 , at which time the UVC was removed. If a PICC was removed for any reason and further central access was required, another PICC was placed. In the control (expectant management) group $(\mathrm{N}=104)$, when the UVC was no longer needed, or by 28 days at the latest, the UVC was removed. Before 28 days if the UVC was removed for any reason and central access was still required, a further UVC was placed. At 28 days, if the infant was not close to full enteral feeds and required central venous access, a PICC was placed at the discretion of the team.

For both groups, the clinical team decided on the overall duration of central venous access, with CVCs removed when the infant no longer required parenteral nutrition, approached full enteral feeds, or had peripheral vascular access. More infants in the early planned removal group than in the expectant management group required percutaneous insertion of a central catheter ( 83 vs 33 ). The report does not specify which other infection control precautions (e.g. practices to scrub the hub before line entry) were taken during the trial, or whether these were standardised for both intervention and control groups.

We assessed all outcomes in an intention-to-treat manner. The primary outcome was time to catheter-related bloodstream infection and incidence of catheter-related infection (defined as symptoms, positive blood culture, CVC in place). We counted each infant only once as having catheter-related infection during the study regardless of future blood culture results. This did not include late-onset bloodstream infections that occurred after removal of the CVC. Secondary outcomes included CVC-related thrombosis, haemorrhage, arrhythmia, pericardial effusion, or pleural effusion. We planned to perform secondary outcome assessment for portal hypertension at age five years, but no data have yet been published.

\section{Excluded studies}

We excluded seven studies (Khilnani 1991; Landers 1991; Davey 1994; Loisel 1996; Boo 1999; Gharehbaghi 2011; Keir 2014; Characteristics of excluded studies).

\section{Risk of bias in included studies}

We included only one trial (Butler O'Hara 2006).

\section{Allocation}

Investigators assigned participating infants to intervention or control using a block randomisation scheme derived from a random numbers table. Allocation took place via opaque randomisation envelopes.

\section{Blinding}

The study group was not blinded to parents, caregivers, or managing clinical staff. It is unclear whether outcome assessment was blinded.

\section{Incomplete outcome data}

Study authors reported all participant data for primary outcomes. Some data for secondary outcomes were missing - some were provided by study authors - as were some one-year follow-up reviews (with participants presumably lost to follow-up, although not stated).

\section{Other potential sources of bias}

We detected potential ascertainment bias. We noted difficulty in obtaining paired blood cultures (from peripheral and catheter) for four of the eight bloodstream infection events in the short-term group in which a non-definitive pathogen (all coagulase-negative staphylococci) was isolated. This may have improved detection of bloodstream infection over the long term in the UVC group, for which paired confirmatory samples were easier to take from the UVC.

\section{Effects of interventions}

See: Summary of findings for the main comparison

\section{Primary outcomes}

- Confirmed bloodstream infection (Analysis 1.1): Trialists reported this as the number of infants with a microbiologically confirmed bloodstream infection during the trial period ( 28 days) when a catheter was in place. Trial data did not show a difference (RR $0.65,95 \% \mathrm{Cl} 0.35$ to 1.22 ; RD $-0.07,95 \% \mathrm{Cl}$ -0.17 to 0.03 ; Figure 2). Results described 7.4 infections per 1000 catheter-days in the short-term group, and 11.5 per 1000 in the long-term group

\section{Figure 2. Forest plot of comparison: 1 Early planned UVC removal vs later planned removal or expectant} management, outcome: 1.1 Bloodstream infection.

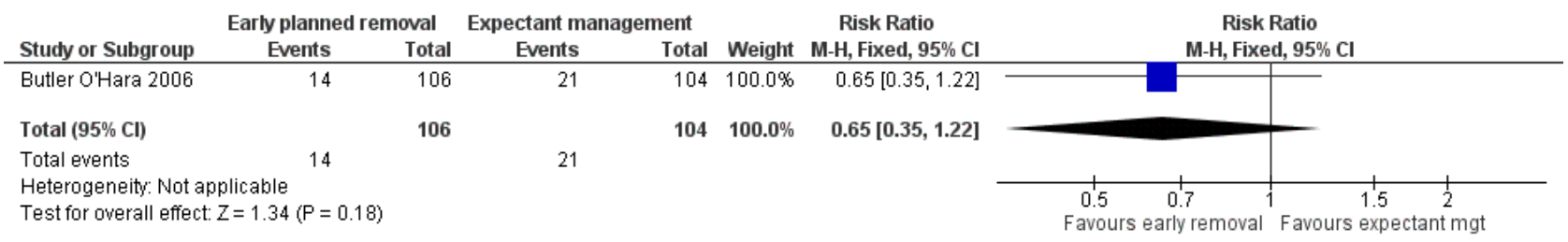


- Confirmed bloodstream infection by type of micro-organism (Analysis 1.2). Data showed no effect on infections with:

* coagulase-negative staphylococci: RR $0.49,95 \% \mathrm{Cl} 0.19$ to 1.26; RD - $0.06,95 \% \mathrm{Cl}-0.13$ to 0.02 ;

* other bacteria: RR $0.61,95 \% \mathrm{Cl} 0.21$ to 1.81 ; RD $-0.03,95 \% \mathrm{Cl}$ -0.09 to 0.04 ; or

* fungi: RR $1.96,95 \% \mathrm{Cl} 0.18$ to $21.31 ; \mathrm{RD} 0.01,95 \% \mathrm{Cl}-0.02$ to 0.04 .

\section{Secondary outcomes}

- Mortality

* Neonatal mortality: not reported

* Death before hospital discharge (Analysis 1.3): Data showed no difference (RR 1.12, $95 \% \mathrm{Cl} 0.42$ to 2.98 ; RD $0.01,95 \% \mathrm{Cl}$ -0.06 to 0.08 ; Figure 3 )

* Death up to one year post term due to all causes: not reported

- Neurodevelopmental outcomes: not reported

- Death or neurological impairment: not reported

- Growth

* Days to regain birth weight: Trial data did not show a statistically significant difference (median 9 (range 0 to 27) vs 10 (0 to 33))

* Average rates of weight gain, linear growth, head growth, and skinfold thickness growth during hospital admission: not reported
- Extravasation injury (Analysis 1.4)

* Subcutaneous extravasation resulting in skin ulceration; 'deep' extravasation resulting in limb swelling: not reported

* 'Central' extravasation - infusate in the pleural, peritoneal, or pericardial space: Data showed no difference in the incidence of pericardial effusion (RR $0.98,95 \% \mathrm{Cl} 0.33$ to 2.94 ; RD -0.0 , $95 \% \mathrm{Cl}-0.06$ to 0.06 ; Figure 4). None of the infants developed a pleural or peritoneal effusion

- Catheter-associated thrombosis necessitating removal of catheter (Analysis 1.5). Trial data did not show a difference (RR $0.33,95 \% \mathrm{Cl} 0.01$ to $7.94 ; \mathrm{RD}-0.01,95 \% \mathrm{Cl}-0.04$ to 0.02 ; Figure 5 )

- Number of cannulas or catheters used per infant to administer parenteral fluids until full enteral feeding established (Analysis 1.6): Trial data show the number of catheters (UVC or PICC) placed until day 28 . The early planned removal group received more catheters on average: MD $0.24(95 \% \mathrm{Cl} 0.05$ to 0.43$)$ (Figure 6)

- Days to full enteral feeding: Trial results did not show a difference (median 23 days (range 7 to 101) vs 22 days (range 7 to 136))

- Central catheter leak, obstruction, or breakage necessitating removal of catheter: Data show this outcome per total number of catheters, not per infant. In the intervention group, 27 of 210 CVCs were removed versus 27 of 181 in the expectant management group

- Other morbidity developing until discharge from hospital

Figure 3. Forest plot of comparison: 1 Early planned UVC removal vs later planned removal or expectant management, outcome: 1.3 All-cause mortality.

\begin{tabular}{|c|c|c|c|c|c|c|c|c|c|}
\hline \multirow[b]{2}{*}{ Study or Subgroup } & \multicolumn{2}{|c|}{ Early planned removal } & \multicolumn{2}{|c|}{ Expectant management } & \multicolumn{2}{|r|}{ Risk Ratio } & \multirow{2}{*}{\multicolumn{2}{|c|}{$\begin{array}{c}\text { Risk Ratio } \\
\text { M-H, Fixed, } 95 \% \text { Cl }\end{array}$}} & Risk of Bias \\
\hline & Events & Total & Events & Total & Weight & M-H, Fixed, $95 \% \mathrm{Cl}$ & & & A B C D E \\
\hline Butler O'Hara 2006 & 8 & 106 & 7 & 104 & $100.0 \%$ & $1.12[0.42,2.98]$ & & & ๑๑? ? \\
\hline Total $(95 \% \mathrm{Cl})$ & & 106 & & 104 & $100.0 \%$ & $1.12[0.42,2.98]$ & & & \\
\hline Total events & 8 & & 7 & & & & & & \\
\hline $\begin{array}{l}\text { Heterogeneity: Not a } \\
\text { Test for overall effec }\end{array}$ & $\begin{array}{l}\text { plicable } \\
Z=0.23(P=\end{array}$ & & & & & & $\begin{array}{cc}1 & 1 \\
0.5 & 0.7 \\
\text { urs early removal }\end{array}$ & $\begin{array}{r}1.5 \\
\text { Favours e }\end{array}$ & \\
\hline
\end{tabular}

Risk of bias legend

(A) Random sequence generation (selection bias)

(B) Allocation concealment (selection bias)

(C) Blinding of participants and personnel (performance bias)

(D) Blinding of outcome assessment (detection bias)

(E) Incomplete outcome data (attrition bias)

Figure 4. Forest plot of comparison: 1 Early planned UVC removal vs later planned removal or expectant management, outcome: 1.4 Pericardial effusion.

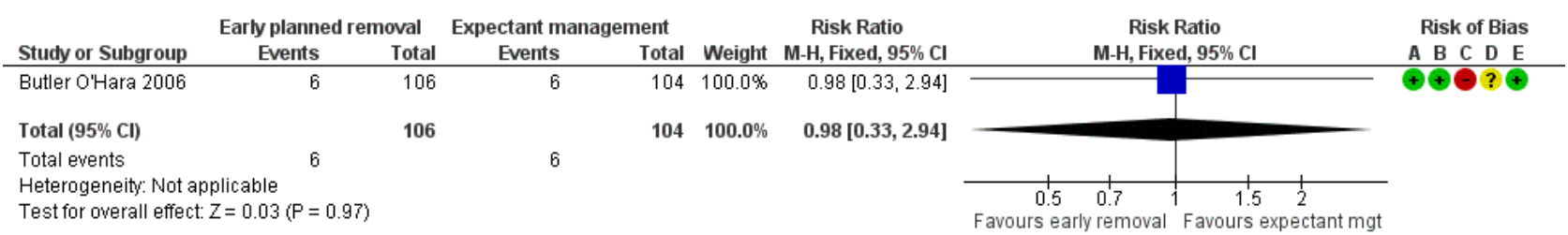

Risk of bias legend

(A) Random sequence generation (selection bias)

(B) Allocation concealment (selection bias)

(C) Blinding of participants and personnel (performance bias)

(D) Blinding of outcome assessment (detection bias)

(E) Incomplete outcome data (attrition bias) 
Figure 5. Forest plot of comparison: 1 Early planned UVC removal vs later planned removal or expectant management, outcome: 1.5 Catheter-associated thrombosis necessitating removal of catheter.

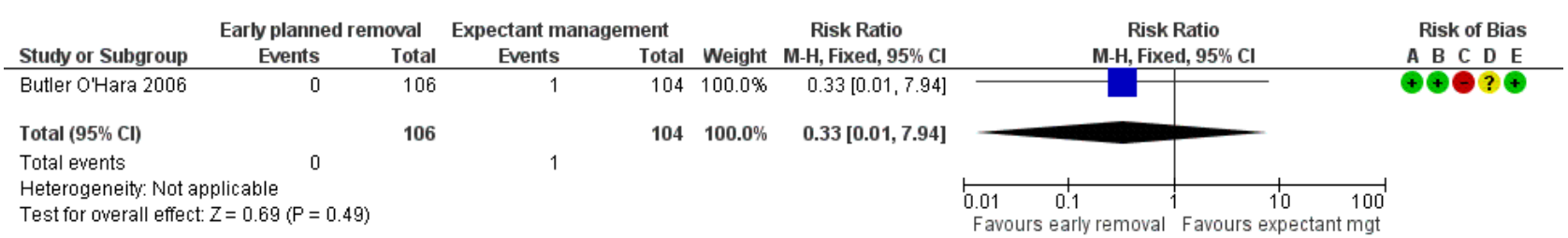

Risk of bias legend

(A) Random sequence generation (selection bias)

(B) Allocation concealment (selection bias)

(C) Blinding of participants and personnel (performance bias)

(D) Blinding of outcome assessment (detection bias)

(E) Incomplete outcome data (attrition bias)

Figure 6. Forest plot of comparison: 1 Early planned UVC removal vs later planned removal or expectant management, outcome: 1.6 Number of cannulas or catheters used per infant.

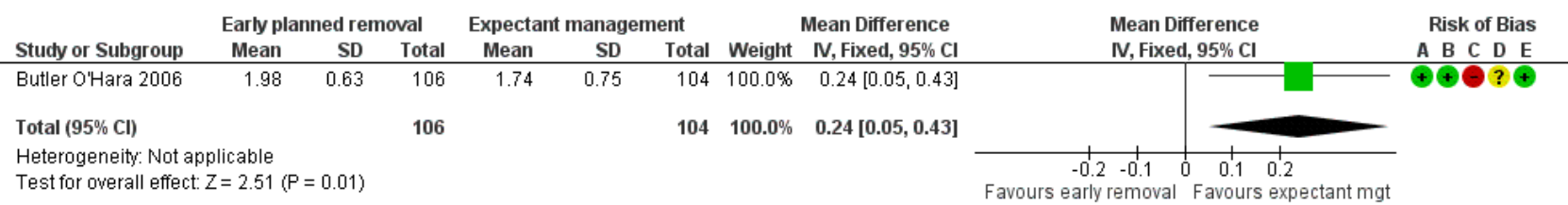

Risk of bias legend

(A) Random sequence generation (selection bias)

(B) Allocation concealment (selection bias)

(C) Blinding of participants and personnel (performance bias)

(D) Blinding of outcome assessment (detection bias)

(E) Incomplete outcome data (attrition bias)

- Bronchopulmonary dysplasia: not reported

- Necrotising enterocolitis (Bell stage 2 or 3) (Analysis 1.7): Trial data did not show a difference (RR $0.62,95 \% \mathrm{Cl} 0.25$ to 1.55; RD $-0.04,95 \% \mathrm{Cl}-0.12$ to 0.04 ; Figure 7 )

- Retinopathy of prematurity: not reported

Figure 7. Forest plot of comparison: 1 Early planned UVC removal vs later planned removal or expectant management, outcome: 1.7 Necrotising enterocolitis (Bell stage 2 or 3 ).

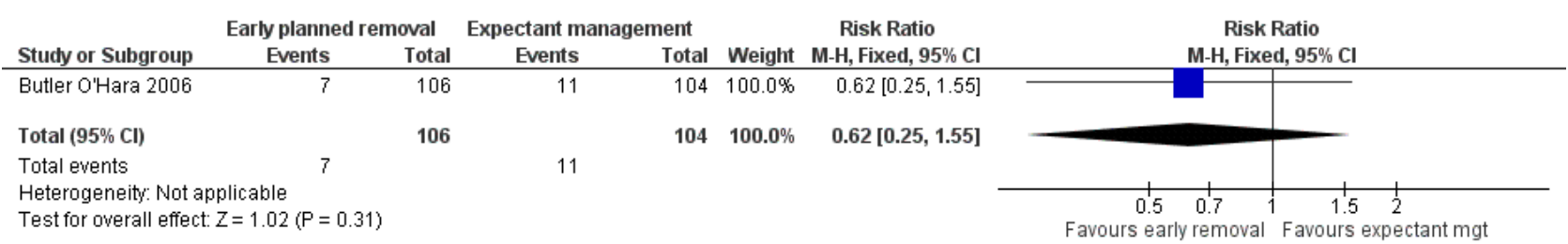

\section{Subgroup analyses}

- Very preterm (<32 weeks) infants (vs infants born at or later than 32 weeks): A vast majority of participants are likely to have been very preterm (average gestational age 27 weeks, SD 2 weeks)

- Prespecified planned duration of UVC placement: All participants had planned UVC placement for 7 to 10 days

\section{DISCUSSION}

\section{Summary of main results}

We found one trial for inclusion in this review (Butler O'Hara 2006). This trial was unblinded but otherwise of good methodological quality. Trial data did not show any effects of the intervention on the incidence of catheter-related bloodstream infection, or on hospital mortality, other catheter-related complications (including thrombosis), or neonatal morbidity (including necrotising enterocolitis).

\section{Overall completeness and applicability of evidence}

We identified one small trial $(N=210)$ for inclusion in this review (Butler O'Hara 2006). Trial data did not provide evidence that a policy of early planned removal of umbilical venous catheters (UVCs) (with replacement by a peripheral cannula or a percutaneously inserted central catheter (PICC) if needed) affected the risk of catheter-related bloodstream infection in newborn infants of birth weight less than 1251 grams. The event rate in 
the control group (20\% incidence of bloodstream infection) is comparable with that of other studies, and findings are likely to be generally applicable to healthcare settings in high-income and middle-income countries with similar populations and care practices (Arnts 2014; Shalabi 2015). The wide 95\% confidence interval $(\mathrm{Cl})$ for the risk ratio (RR) estimate (0.35 to 1.22 ), however, indicates that a substantial and important effect on risk of bloodstream infection cannot yet be excluded.

The included trial reported catheter-related bloodstream infection, that is, laboratory culture of a pathogenic micro-organism from blood (sampled from a peripheral site) "while a catheter was in place". This definition is similar to the US Centers for Disease Control and Prevention (CDC) definition of central line-associated bloodstream infection that is used in surveillance studies, and it is consistent with the plausible effect of the intervention in reducing bloodstream infection risk by removing intravascular devices that may act as a portal or reservoir for infecting organisms.

The primary finding that rates of bloodstream infection were not statistically significantly different between groups is possibly due to the fact that infants in each group had a central venous catheter (CVC) (either a UVC, or a UVC followed by a PICC) in place for similar total durations up to 28 days. Observational studies do not show differences in the risk of bloodstream infection among infants with a UVC versus a PICC in place (Arnts 2014; Shalabi 2015). More infants in the early planned removal group than in the expectant management group, however, required insertion of a PICC (83 vs 33 ), and infants in the early planned removal group required placement of, on average, 0.24 more CVCs during the 28day trial period. The importance of these differences for infants, families, caregivers, and services (including the impact on costeffectiveness) is uncertain.

Similarly, available data are insufficient to permit exclusion of plausible and important effects on secondary outcomes. For example, the wide $95 \% \mathrm{Cl}$ bounds for the estimate of effect on mortality before hospital discharge include risk reduced by more than half and risk increased more than three-fold. This trial has not reported long-term (post-hospital discharge) data.

The included trial recruited only infants of birth weight less than 1251 grams, and whilst this group makes up a large proportion of infants who receive UVCs in neonatal units, a large number of heavier babies also require this form of central venous access. The incidence of, and risks for, CVC-associated infection vary between very low birth weight and heavier infants, and data from this trial may not be directly applicable to, for example, term or near-term infants.

\section{Quality of the evidence}

Although allocation was concealed, the trial intervention was not blinded to caregivers and investigators, and surveillance bias may have influenced assessment of some outcomes, including bloodstream infection. Clinicians' subjective assessment of when to investigate for infection may have been affected by the perception that longer dwell times increased the risk of catheterrelated infection. The unblinded design may have influenced other care practices. For example, the perception that longer-term UVC placement might increase the risk of infection may influence adherence of healthcare staff to other infection control practices.

These trial design concerns, together with imprecision of estimates of effect, mean that the overall quality of evidence for key outcomes (i.e. bloodstream infection, mortality, catheterassociated thrombosis) is "low" according to GRADE Working Group grades of evidence (Summary of findings for the main comparison). Further research is very likely to have an important impact on our confidence in current estimates of effect and is likely to change the estimates.

\section{Potential biases in the review process}

We found only one trial for inclusion in this review. Although we conducted a comprehensive search, including a search of conference proceedings, we cannot exclude fully the possibility of publication bias because we do not know whether other published (but not indexed) or unpublished trials have been conducted.

\section{AUTHORS' CONCLUSIONS}

\section{Implications for practice}

We found a paucity of trial data to support or refute the hypothesis that early planned removal of umbilical venous catheters (UVCs) affects risk of infection among newborn infants. The only trial conducted to address this question does not provide sufficient evidence to guide policy or clinical practice.

\section{Implications for research}

Given the potential for benefit and harm to be associated with timing of removal of the UVC from a neonate, a pragmatic randomised controlled trial of early planned removal versus expectant management may be warranted. Such a trial might include infants at elevated risk of catheter-related bloodstream infection because of an anticipated need for a prolonged period of central vascular access for delivery of parenteral nutrition (e.g. extremely preterm infants, growth-compromised infants) and might address primarily the effect of early planned removal (e.g. by 7 to 14 days) on risk of catheter-related bloodstream infection (defined by established and validated criteria). A large, simple, pragmatic trial would be needed to allow assessment of a modest but important reduction in the incidence of bloodstream infection (e.g. > 2000 participants to provide $90 \%$ power to detect $25 \%$ risk ratio (RR) reduction), as well as effects on other catheter- and infection-related complications.

\section{ACKN OWLEDGEMENTS}

We thank the trial investigators for providing unpublished data (Butler O'Hara 2006). 


\section{R E F E R E N C E S}

\section{References to studies included in this review}

Butler O'Hara 2006 \{published and unpublished data\}

Butler-O'Hara M, Buzzard.CJ, Reubens L, McDermott MP, DiGrazio W, D'Angio CT. A randomized trial comparing long-term and short-term use of umbilical venous catheters in premature infants with birth weights of less than 1251 grams. Pediatrics 2006;118(1):e25-35. [DOI: 10.1542/peds.2005-1880; PUBMED: 16785289]

\section{References to studies excluded from this review}

Boo 1999 \{published data only\}

Boo NY, Wong NC, Zulkifli SS, Lye MS. Risk factors associated with umbilical vascular catheter-associated thrombosis in newborn infants. Journal of Paediatrics and Child Health 1999;35(5):460-5. [PUBMED: 10571759]

\section{Davey 1994 \{published data only\}}

Davey AM, Wagner CL, Cox C, Kendig JW. Feeding premature infants while low umbilical artery catheters are in place: a prospective, randomized trial. Journal of Pediatrics 1994;124(5 Pt 1):795-9. [PUBMED: 8176571]

\section{Gharehbaghi 2011 \{published data only\}}

Gharehbaghi MM, Nemati M, Hosseinpour SS, Taei R, Ghargharechi R. Umbilical vascular catheter associated portal vein thrombosis detected by ultrasound. Indian Journal of Pediatrics 2011;78(2):161-4. [DOI: 10.1007/s12098-010-0223-x; PUBMED: 21063811]

\section{Keir 2014 \{published data only\}}

Keir A, Giesinger R, Dunn M. How long should umbilical venous catheters remain in place in neonates who require long-term $(>/=5-7$ days) central venous access?. Journal of Paediatrics and Child Health 2014;50(8):649-52. [PUBMED: 25080979]

Khilnani 1991 \{published data only\} Khilnani P, Goldstein B, Todres ID. Double lumen umbilical venous catheters in critically ill neonates: a randomized prospective study. Critical Care Medicine 1991;19(11):1348-51. [PUBMED: 1935151]

\section{Landers 1991 \{published data only\}}

Landers S, Moise AA, Fraley JK, Smith EO, Baker CJ. Factors associated with umbilical catheter-related sepsis in neonates. American Journal of Diseases of Children 1991;145(6):675-80. [PUBMED: 1903588]

\section{Loisel 1996 \{published data only\}}

Loisel DB, Smith MM, MacDonald MG, Martin GR. Intravenous access in newborn infants: impact of extended umbilical venous catheter use on requirement for peripheral venous lines. Journal of Perinatology 1996;16(6):461-6. [PUBMED: 8979185]

\section{Additional references}

\section{Adams-Chapman 2006}

Adams-Chapman I, Stoll BJ. Neonatal infection and longterm neurodevelopmental outcome in the preterm infant. Current Opinion in Infectious Diseases 2006;19(3):290-7. [DOI: 10.1097/01.qco.0000224825.57976.87; PUBMED: 16645492]

\section{Arnts 2014}

Arnts IJ, Bullens LM, Groenewoud JM, Liem KD. Comparison of complication rates between umbilical and peripherally inserted central venous catheters in newborns. Journal of Obstetric, Gynecologic, and Neonatal Nursing 2014;43(2):205-15. [DOI: 10.1111/1552-6909.12278; PUBMED: 24502854]

\section{Balain 2015}

Balain M, Oddie SJ, McGuire W. Antimicrobial-impregnated central venous catheters for prevention of catheter-related bloodstream infection in newborn infants. Cochrane Database of Systematic Reviews 2015, Issue 9. [DOI: 10.1002/14651858.CD011078.pub2; PUBMED: 26409791]

\section{Bassler 2009}

Bassler D, Stoll BJ, Schmidt B, Asztalos EV, Roberts RS, Robertson CM, et al. Trial of Indomethacin Prophylaxis in Preterms Investigators. Using a count of neonatal morbidities to predict poor outcome in extremely low birth weight infants: added role of neonatal infection. Pediatrics 2009;123(1):313-8. [DOI: 10.1542/peds.2008-0377; PUBMED: 19117897]

\section{Butler-O'Hara 2012}

Butler-O'Hara M, D'Angio CT, Hoey H, Stevens TP. An evidencebased catheter bundle alters central venous catheter strategy in newborn infants. Journal of Pediatrics 2012;160(6):972-7.e2. [DOI: 10.1016/j.jpeds.2011.12.004; PUBMED: 22240109]

\section{Chapman 2003}

Chapman RL, Faix RG. Persistent bacteremia and outcome in late onset infection among infants in a neonatal intensive care unit. Pediatric Infectious Disease Journal 2003;22(1):17-21. [DOI: 10.1097/01.inf.0000042922.10767.10; PUBMED: 12544403

\section{Ehrenkranz 2005}

Ehrenkranz RA, Walsh MC, Vohr BR, Jobe AH, Wright LL, Fanaroff AA, et al. National Institutes of Child Health and Human Development Neonatal Research Network. Validation of the National Institutes of Health consensus definition of bronchopulmonary dysplasia. Pediatrics 2005;116(6):1353-60. [DOI: 10.1542/peds.2005-0249; PUBMED: 16322158]

\section{Gordon 2016}

Gordon A, Greenhalgh M, McGuire W. Early planned removal versus expectant management of peripherally inserted central catheters to prevent infection in newborn infants. Cochrane Database of Systematic Reviews 2016, Issue 4. [DOI: 10.1002/14651858.CD012141] 


\section{GRADEproGDT [Computer program]}

McMaster University (developed by Evidence Prime). GRADEproGDT. Version accessed 10 May 2017. Hamilton (ON): McMaster University (developed by Evidence Prime), 2015. gradepro.org.

\section{Green 1998}

Green C, Yohannan MD. Umbilical arterial and venous catheters: placement, use, and complications. Neonatal Network 1998;17(6):23-8. [PUBMED: 9832755]

\section{Grizelj 2014}

Grizelj R, Vukovic J, Bojanic K, Loncarevic D, Stern-Padovan R, Filipovic-Grcic B, et al. Severe liver injury while using umbilical venous catheter: case series and literature review. American Journal of Perinatology 2014;31(11):965-74. [DOI: 10.1055/ s-0034-1370346; PUBMED: 24590868]

\section{Guyatt 2011a}

Guyatt G, Oxman AD, Akl EA, Kunz R, Vist G, Brozek J, et al. GRADE guidelines: 1. Introduction - GRADE evidence profiles and summary of findings tables. Journal of Clinical Epidemiology 2011;64(4):383-94. [PUBMED: 21195583]

\section{Guyatt 2011b}

Guyatt GH, Oxman AD, Vist G, Kunz R, Brozek J, Alonso-Coello P, et al. GRADE guidelines: 4. Rating the quality of evidence study limitations (risk of bias). Journal of Clinical Epidemiology 2011;64(4):407-15. [PUBMED: 21247734]

\section{Guyatt 2011c}

Guyatt GH, Oxman AD, Kunz R, Woodcock J, Brozek J, Helfand M, et al. GRADE guidelines: 7 . Rating the quality of evidence - inconsistency. Journal of Clinical Epidemiology 2011;64(12):1294-302. [PUBMED: 21803546]

\section{Guyatt 2011d}

Guyatt GH, Oxman AD, Kunz R, Brozek J, Alonso-Coello P, Rind $D$, et al. GRADE guidelines 6 . Rating the quality of evidence - imprecision. Journal of Clinical Epidemiology 2011;64(12):1283-93. [PUBMED: 21839614]

\section{Guyatt 2011e}

Guyatt GH, Oxman AD, Kunz R, Woodcock J, Brozek J, Helfand M, et al. GRADE guidelines: 8. Rating the quality of evidence - indirectness. Journal of Clinical Epidemiology 2011;64(12):1303-10. [PUBMED: 21802903]

\section{Hermans 2007}

Hermans D, Talbotec C, Lacaille F, Goulet O, Ricour C, Colomb V. Early central catheter infections may contribute to hepatic fibrosis in children receiving long-term parenteral nutrition. Journal of Pediatric Gastroenterology and Nutrition 2007;44(4):459-63. [DOI: 10.1097/MPG.0b013e318031a5c7; PUBMED: 17414144$]$

\section{Hermansen 2005}

Hermansen MC, Hermansen MG. Intravascular catheter complications in the neonatal intensive care unit. Clinics in Perinatology 2005;32(1):141-56. [DOI: 10.1016/j.clp.2004.11.005; PUBMED: 15777826$]$

\section{Higgins 2011}

Higgins JPT, Green S (editors). Cochrane Handbook for Systematic Reviews of Interventions Version 5.1.0 (updated March 2011). The Cochrane Collaboration, 2011. handbook.cochrane.org.

\section{Hollingsworth 2015}

Hollingsworth C, Clarke P, Sharma A, Upton M. National survey of umbilical venous catheterisation practices in the wake of two deaths. Archives of Disease in Childhood. Fetal and Neonatal Edition 2015; Vol. 100, issue 4:F371-2. [DOI: 10.1136/ archdischild-2015-308327; PUBMED: 25862724]

\section{ICROP 2005}

International Committee for the Classification of Retinopathy of Prematurity. The International Classification of Retinopathy of Prematurity revisited. Archives of Ophthalmology 2005;123(7):991-9. [DOI: 10.1001/archopht.123.7.991; PUBMED: 16009843]

\section{Kim 2001}

Kim JH, Lee YS, Kim SH, Lee SK, Lim MK, Kim HS. Does umbilical vein catheterization lead to portal vein thrombosis? Prospective US evaluation of 100 neonates. Radiology 2001;219(3):645-50. [DOI: 10.1148/radiology.219.3.r01jn17645; PUBMED: 11376248]

\section{Lahra 2009}

Lahra MM, Beeby PJ, Jeffery HE. Intrauterine inflammation, neonatal sepsis, and chronic lung disease: a 13-year hospital cohort study. Pediatrics 2009;123(5):1314-9. [DOI: 10.1542/ peds.2008-0656; PUBMED: 19403497]

\section{Mutlu 2016}

Mutlu M, Aslan Y, Kul S, Yilmaz G. Umbilical venous catheter complications in newborns: a 6-year single-center experience. Journal of Maternal-Fetal \& Neonatal Medicine 2016; Vol. 29, issue 17:2817-22. [DOI: 10.3109/14767058.2015.1105952; PUBMED: 26452458]

\section{Narang 2009}

Narang S, Roy J, Stevens TP, Butler-O'Hara M, Mullen CA, D'Angio CT. Risk factors for umbilical venous catheterassociated thrombosis in very low birth weight infants. Pediatric Blood Cancer 2009;52(1):75-9. [DOI: 10.1002/pbc.21714; PUBMED: 18680150$]$

\section{Nash 2006}

Nash P. Umbilical catheters, placement, and complication management. Journal of Infusion Nursing 2006;29(6):346-52. [PUBMED: 17122690]

\section{O'Grady 2011}

O'Grady NP, Alexander M, Burns LA, Dellinger EP, Garland J, Heard SO, et al. Healthcare Infection Control Practices Advisory Committee (HICPAC). Guidelines for the prevention of intravascular catheter-related infections. Clinical Infectious Diseases 2011;52(9):e162-93. [DOI: 10.1093/cid/cir257; PUBMED: 21460264] 


\section{Panetta 2000}

Panetta J, Morley C, Betheras R. Ascites in a premature baby due to parenteral nutrition from an umbilical venous catheter. Journal of Paediatrics and Child Health 2000;36(2):197-8. [PUBMED: 10809532]

\section{Payne 2004}

Payne NR, Carpenter JH, Badger GJ, Horbar JD, Rogowski J. Marginal increase in cost and excess length of stay associated with nos surviving very low birth weight infants. Pediatrics 2004;114(2):348-55. [PUBMED: 15286215]

\section{Pereira 1992}

Pereira GR, Lim BK, Ing C, Medeiros HF. Umbilical vs peripheral vein catheterization for parenteral nutrition in sick premature neonates. Yonsei Medical Journal 1992;33(3):224-31. [DOI: 10.3349/ymj.1992.33.3.224; PUBMED: 1292246]

\section{RevMan 2014 [Computer program]}

Nordic Cochrane Centre, The Cochrane Collaboration. Review Manager 5 (RevMan 5). Version 5.3. Copenhagen: Nordic Cochrane Centre, The Cochrane Collaboration, 2014.

\section{Saint 2000}

Saint S, Veenstra DL, Lipsky BA. The clinical and economic consequences of nosocomial central venous catheter-related infection: are antimicrobial catheters useful?. Infection Control and Hospital Epidemiology 2000;21(6):375-80. [DOI: 10.1086/501776; PUBMED: 10879567]

\section{Schulman 2011}

Schulman J, Stricof R, Stevens TP, Horgan M, Gase K, Holzman IR, et al. New York State Regional Perinatal Care Centers. Statewide NICU central-line-associated bloodstream infection rates decline after bundles and checklists. Pediatrics 2011;127(3):436-44. [DOI: 10.1542/peds.2010-2873; PUBMED: 21339265]

\section{Schünemann 2013}

Schünemann H, Brożek J, Guyatt G, Oxman A, editors. GRADE Working Group. GRADE Handbook for Grading Quality of Evidence and Strength of Recommendations. https:// gdt.gradepro.org/app/handbook/handbook.html. Updated October 2013.

\section{Seguin 1994}

Seguin J, Fletcher MA, Landers S, Brown D, Macpherson T. Umbilical venous catheterizations: audit by the Study Group for Complications of Perinatal Care. American Journal of Perinatology 1994;11(1):67-70. [DOI: 10.1055/s-2007-994540; PUBMED: 8155217]

\section{Shah 2008}

Shah DK, Doyle LW, Anderson PJ, Bear M, Daley AJ, Hunt RW, et al. Adverse neurodevelopment in preterm infants with postnatal sepsis or necrotizing enterocolitis is mediated by white matter abnormalities on magnetic resonance imaging at term. Journal of Pediatrics 2008;153(2):170-5. [DOI: 10.1016/j.jpeds.2008.02.033; PUBMED: 18534228]

\section{Shahid 2014}

Shahid S, Dutta S, Symington A, Shivananda S, McMaster University NICU. Standardizing umbilical catheter usage in preterm infants. Pediatrics 2014;133(6):e1742-52. [DOI: 10.1542/ peds.2013-1373; PUBMED: 24843063]

\section{Shalabi 2015}

Shalabi M, Adel M, Yoon E, Aziz K, Lee S, Shah PS, Canadian

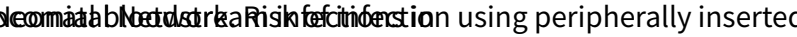
central and umbilical catheters in preterm neonates. Pediatrics 2015;136(6):1073-9. [DOI: 10.1542/peds.2015-2710; PUBMED: 26574592]

\section{Shareena 2008}

Shareena I, Khu YS, Cheah FC. Intraperitoneal extravasation of total parenteral nutrition infusate from an umbilical venous catheter. Singapore Medical Journal 2008;49(2):e35-6. [PUBMED: 18301823]

\section{Stoll 2004}

Stoll BJ, Hansen NI, Adams-Chapman I, Fanaroff AA, Hintz SR, Vohr B, et al. National Institute of Child Health and Human Development Neonatal Research Network. Neurodevelopmental and growth impairment among extremely lowbirth-weight infants with neonatal infection. JAMA 2004;292(19):2357-65. [DOI: 10.1001/jama.292.19.2357; PUBMED: 15547163

\section{Taylor 2014}

Taylor JE, McDonald SJ, Tan K. A survey of central venous catheter practices in Australian and New Zealand tertiary neonatal units. Australian Critical Care 2014;27(1):36-42. [DOI: 10.1016/j.aucc.2013.11.002; PUBMED: 24315154]

\section{Taylor 2015}

Taylor JE, Tan K, Lai NM, McDonald SJ. Antibiotic lock for the prevention of catheter-related infection in neonates. Cochrane Database of Systematic Reviews 2015, Issue 6. [DOI: 10.1002/14651858.CD010336.pub2; PUBMED: 26040840]

\section{Traen 2005}

Traen M, Schepens E, Laroche S, van Overmeire B. Cardiac tamponade and pericardial effusion due to venous umbilical catheterization. Acta Paediatrica 2005;94(5):626-8. [DOI: 10.1080/08035250410025492; PUBMED: 16188754]

\section{Walsh 1986}

Walsh MC, Kliegman RM. Necrotizing enterocolitis: treatment based on staging criteria. Pediatric Clinics of North America 1986;33(1):179-201. [PUBMED: 3081865]

\section{Wu 2012}

Wu J, Mu D. Vascular catheter-related complications in newborns. Journal of Paediatrics and Child Health 2012;48(2):E91-5. [DOI: 10.1111/j.1440-1754.2010.01934.x; PUBMED: 21199061]

\section{Zingg 2011}

Zingg W, Posfay-Barbe KM, Pfister RE, Touveneau S, Pittet D. Individualized catheter surveillance among neonates: a prospective, 8-year, single-center experience. Infection 
Control and Hospital Epidemiology 2011;32(1):42-9. [DOI:

10.1086/657634; PUBMED: 21121817]

CHARACTERISTICS OF STUDIES

Characteristics of included studies [ordered by study ID]

Butler O'Hara 2006

\begin{tabular}{ll}
\hline Methods & Randomised controlled trial \\
\hline Participants & Infants with birth weight < 1251 grams and a UVC in situ (N=210) \\
\hline Interventions & $\begin{array}{l}\text { Short-term (<10 days) UVC use followed by PICC line placement vs expectant management (UVC in } \\
\text { place up to } 28 \text { days) }\end{array}$ \\
\hline Outcomes & $\begin{array}{l}\text { Incidence of microbiologically confirmed CVC-related bloodstream infection (CVC in place) } \\
\text { Catheter-associated thrombus (detected by ultrasound surveillance), haemorrhage, arrhythmia, peri- } \\
\text { cardial effusion, or pleural effusion } \\
\text { Days to full feeds and rate of weight gain, and incidence of feeding intolerance and necrotising entero- } \\
\text { colitis }\end{array}$ \\
\hline Notes & Study authors provided unpublished data on days to full feeding and days to regain birth weight
\end{tabular}

\section{Risk of bias}

\begin{tabular}{|c|c|c|}
\hline Bias & Authors' judgement & Support for judgement \\
\hline $\begin{array}{l}\text { Random sequence genera- } \\
\text { tion (selection bias) }\end{array}$ & Low risk & Random number table. Block randomisation in groups of 10 for 2 strata \\
\hline $\begin{array}{l}\text { Allocation concealment } \\
\text { (selection bias) }\end{array}$ & Low risk & Opaque sealed envelopes \\
\hline $\begin{array}{l}\text { Blinding of participants } \\
\text { and personnel (perfor- } \\
\text { mance bias) } \\
\text { All outcomes }\end{array}$ & High risk & Study group assignments were not masked \\
\hline $\begin{array}{l}\text { Blinding of outcome as- } \\
\text { sessment (detection bias) } \\
\text { All outcomes }\end{array}$ & Unclear risk & $\begin{array}{l}\text { It is not stated who measured outcomes, and whether those who performed } \\
\text { measurements were blinded }\end{array}$ \\
\hline $\begin{array}{l}\text { Incomplete outcome data } \\
\text { (attrition bias) } \\
\text { All outcomes }\end{array}$ & Low risk & Primary outcomes: All participants were accounted for \\
\hline
\end{tabular}

CVC: central venous catheter.

PICC: peripherally inserted central catheter.

UVC: umbilical venous catheter.

Characteristics of excluded studies [ordered by study ID]

\begin{tabular}{ll}
\hline Study & Reason for exclusion \\
\hline Boo 1999 & Not an RCT \\
\hline \hline
\end{tabular}




\begin{tabular}{ll}
\hline Study & Reason for exclusion \\
\hline Davey 1994 & RCT of early vs delayed enteral feeding in infants with umbilical catheters in situ \\
\hline Gharehbaghi 2011 & Not an RCT \\
\hline Keir 2014 & Not an RCT \\
\hline Khilnani 1991 & RCT of single- vs double-lumen UVC (not duration of use) \\
\hline Landers 1991 & Not an RCT \\
\hline Loisel 1996 & RCT of single- vs double-lumen UVC use for up to 14 days (not an RCT on duration of use) \\
\hline
\end{tabular}

RCT: randomised controlled trial.

UVC: umbilical venous catheter.

\section{DATA AND ANALYSES}

\section{Comparison 1. Early planned UVC removal vs later planned removal or expectant management}

\begin{tabular}{|c|c|c|c|c|}
\hline Outcome or subgroup title & No. of studies & $\begin{array}{l}\text { No. of partici- } \\
\text { pants }\end{array}$ & Statistical method & Effect size \\
\hline 1 Bloodstream infection & 1 & 210 & Risk Ratio (M-H, Fixed, 95\% Cl) & $0.65[0.35,1.22]$ \\
\hline $\begin{array}{l}2 \text { Bloodstream infection by mi- } \\
\text { cro-organism }\end{array}$ & 1 & & Risk Ratio (M-H, Fixed, 95\% Cl) & Subtotals only \\
\hline $\begin{array}{l}2.1 \text { Coagulase-negative staphylo- } \\
\text { coccus }\end{array}$ & 1 & 210 & Risk Ratio (M-H, Fixed, 95\% Cl) & $0.49[0.19,1.26]$ \\
\hline 2.2 Other bacteria & 1 & 210 & Risk Ratio (M-H, Fixed, 95\% Cl) & $0.61[0.21,1.81]$ \\
\hline 2.3 Fungi & 1 & 210 & Risk Ratio (M-H, Fixed, 95\% Cl) & $1.96[0.18,21.31]$ \\
\hline 3 All-cause mortality & 1 & 210 & Risk Ratio (M-H, Fixed, 95\% Cl) & $1.12[0.42,2.98]$ \\
\hline 4 Pericardial effusion & 1 & 210 & Risk Ratio (M-H, Fixed, 95\% Cl) & $0.98[0.33,2.94]$ \\
\hline $\begin{array}{l}5 \text { Catheter-associated thrombosis } \\
\text { necessitating removal of catheter }\end{array}$ & 1 & 210 & Risk Ratio (M-H, Fixed, 95\% Cl) & $0.33[0.01,7.94]$ \\
\hline $\begin{array}{l}6 \text { Number of cannulas or catheters } \\
\text { used per infant }\end{array}$ & 1 & 210 & $\begin{array}{l}\text { Mean Difference (IV, Fixed, 95\% } \\
\mathrm{CI} \text { ) }\end{array}$ & $0.24[0.05,0.43]$ \\
\hline $\begin{array}{l}7 \text { Necrotising enterocolitis (Bell } \\
\text { stage } 2 \text { or } 3 \text { ) }\end{array}$ & 1 & 210 & Risk Ratio (M-H, Fixed, 95\% Cl) & $0.62[0.25,1.55]$ \\
\hline
\end{tabular}


Analysis 1.1. Comparison 1 Early planned UVC removal vs later planned removal or expectant management, Outcome 1 Bloodstream infection.

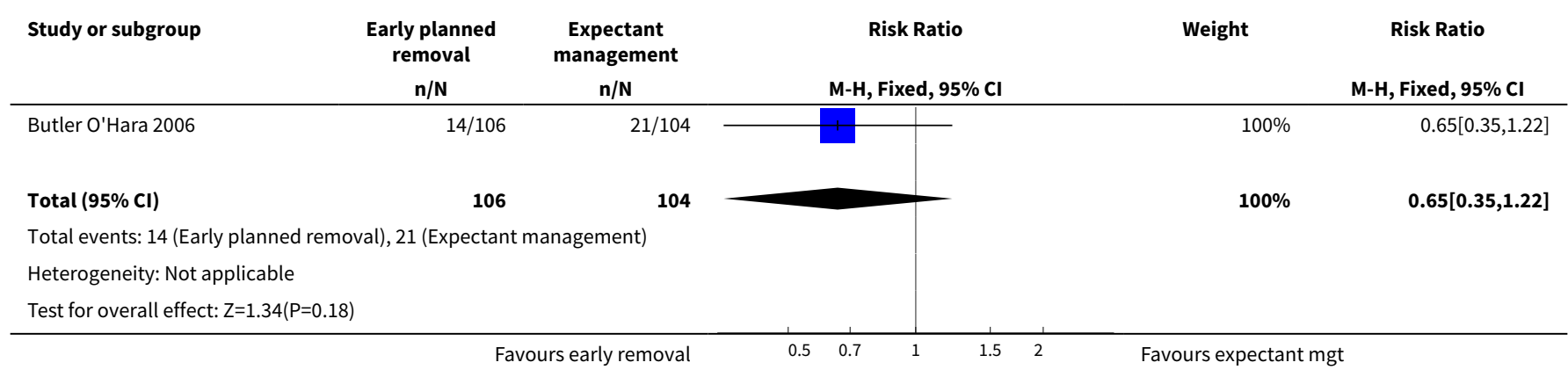

Analysis 1.2. Comparison 1 Early planned UVC removal vs later planned removal or expectant management, Outcome 2 Bloodstream infection by micro-organism.

\begin{tabular}{|c|c|c|c|c|c|}
\hline Study or subgroup & $\begin{array}{c}\text { Early planned } \\
\text { removal } \\
n / N\end{array}$ & $\begin{array}{l}\text { Control } \\
\mathbf{n} / \mathbf{N}\end{array}$ & $\begin{array}{c}\text { Risk Ratio } \\
\text { M-H, Fixed, 95\% Cl }\end{array}$ & Weight & $\begin{array}{c}\text { Risk Ratio } \\
\text { M-H, Fixed, 95\% CI }\end{array}$ \\
\hline \multicolumn{6}{|c|}{ 1.2.1 Coagulase-negative staphylococcus } \\
\hline Butler O'Hara 2006 & $6 / 106$ & $12 / 104$ & - & $100 \%$ & $0.49[0.19,1.26]$ \\
\hline Subtotal $(95 \% \mathrm{Cl})$ & 106 & 104 & & $100 \%$ & $0.49[0.19,1.26]$ \\
\hline \multicolumn{6}{|c|}{ Total events: 6 (Early planned removal), 12 (Control) } \\
\hline \multicolumn{6}{|c|}{ Heterogeneity: Tau $^{2}=0 ; \mathrm{Chi}^{2}=0, \mathrm{df}=0(\mathrm{P}<0.0001) ; \mathrm{I}^{2}=100 \%$} \\
\hline \multicolumn{6}{|c|}{ Test for overall effect: $Z=1.48(P=0.14)$} \\
\hline \multicolumn{6}{|l|}{ 1.2.2 Other bacteria } \\
\hline Butler O'Hara 2006 & $5 / 106$ & $8 / 104$ & & $100 \%$ & $0.61[0.21,1.81]$ \\
\hline Subtotal $(95 \% \mathrm{Cl})$ & 106 & 104 & & $100 \%$ & $0.61[0.21,1.81]$ \\
\hline \multicolumn{6}{|c|}{ Total events: 5 (Early planned removal), 8 (Control) } \\
\hline \multicolumn{6}{|c|}{ Test for overall effect: $\mathrm{Z}=0.88(\mathrm{P}=0.38)$} \\
\hline \multicolumn{6}{|l|}{ 1.2.3 Fungi } \\
\hline Butler O'Hara 2006 & $2 / 106$ & $1 / 104$ & 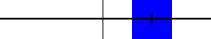 & $100 \%$ & $1.96[0.18,21.31]$ \\
\hline Subtotal $(95 \% \mathrm{Cl})$ & 106 & 104 & & $100 \%$ & $1.96[0.18,21.31]$ \\
\hline \multicolumn{6}{|c|}{ Total events: 2 (Early planned removal), 1 (Control) } \\
\hline \multicolumn{6}{|c|}{ Heterogeneity: Not applicable } \\
\hline \multicolumn{6}{|c|}{ Test for overall effect: $Z=0.55(P=0.58)$} \\
\hline Test for subgroup di & $13, d f=1(P=0.57)$, & & & & \\
\hline
\end{tabular}

\section{Analysis 1.3. Comparison 1 Early planned UVC removal vs later planned removal or expectant management, Outcome 3 All-cause mortality.}

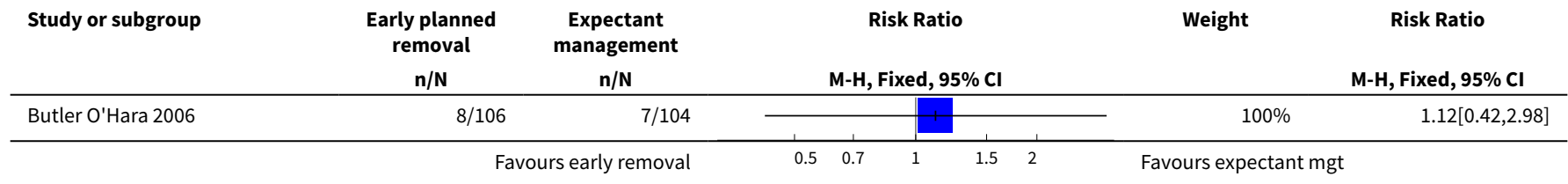




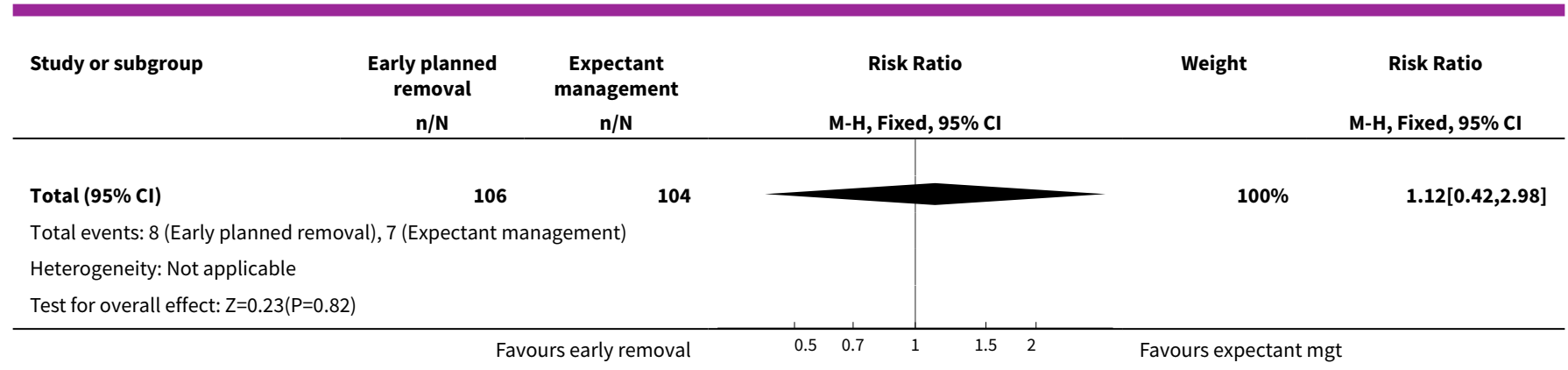

Analysis 1.4. Comparison 1 Early planned UVC removal vs later planned removal or expectant management, Outcome 4 Pericardial effusion.

\begin{tabular}{|c|c|c|c|c|c|}
\hline Study or subgroup & $\begin{array}{c}\text { Early planned } \\
\text { removal } \\
n / N\end{array}$ & $\begin{array}{c}\text { Expectant } \\
\text { management } \\
n / N\end{array}$ & $\begin{array}{c}\text { Risk Ratio } \\
\text { M-H, Fixed, } 95 \% \mathrm{CI}\end{array}$ & Weight & $\begin{array}{l}\text { Risk Ratio } \\
\text { Fixed, } 95 \% \mathrm{Cl}\end{array}$ \\
\hline Butler O'Hara 2006 & $6 / 106$ & $6 / 104$ & 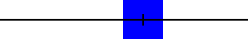 & $100 \%$ & $0.98[0.33,2.94]$ \\
\hline Total $(95 \% \mathrm{Cl})$ & 106 & 104 & & $100 \%$ & $0.98[0.33,2.94]$ \\
\hline \multicolumn{6}{|c|}{ Total events: 6 (Early planned removal), 6 (Expectant management) } \\
\hline \multicolumn{6}{|c|}{ Test for overall effect: $\mathrm{Z}=0.03(\mathrm{P}=0.97)$} \\
\hline
\end{tabular}

Analysis 1.5. Comparison 1 Early planned UVC removal vs later planned removal or expectant management, Outcome 5 Catheter-associated thrombosis necessitating removal of catheter.

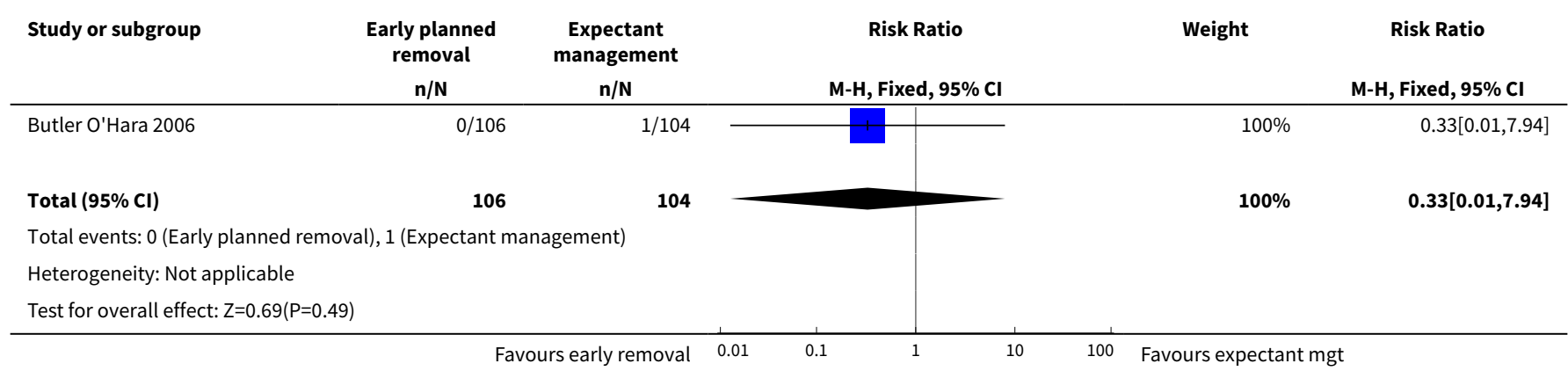

Analysis 1.6. Comparison 1 Early planned UVC removal vs later planned removal or expectant management, Outcome 6 Number of cannulas or catheters used per infant.

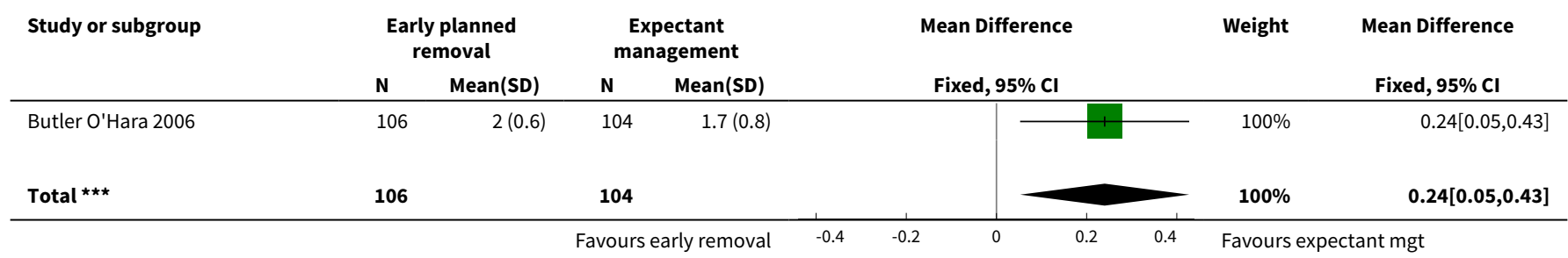




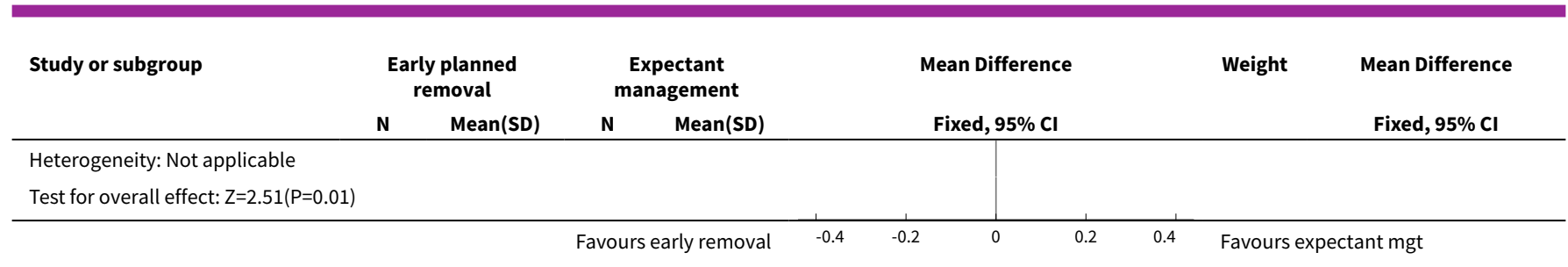

Analysis 1.7. Comparison 1 Early planned UVC removal vs later planned removal or expectant management, Outcome 7 Necrotising enterocolitis (Bell stage 2 or 3 ).

\begin{tabular}{|c|c|c|c|c|c|}
\hline Study or subgroup & $\begin{array}{c}\text { Early planned } \\
\text { removal } \\
n / N\end{array}$ & $\begin{array}{c}\text { Expectant } \\
\text { management } \\
n / N \\
\end{array}$ & $\begin{array}{c}\text { Risk Ratio } \\
\text { M-H, Fixed, 95\% CI }\end{array}$ & Weight & $\begin{array}{c}\text { Risk Ratio } \\
\text { M-H, Fixed, } 95 \% \mathrm{Cl} \\
\end{array}$ \\
\hline Butler O'Hara 2006 & $7 / 106$ & $11 / 104$ & - & $100 \%$ & $0.62[0.25,1.55]$ \\
\hline Total $(95 \% \mathrm{Cl})$ & 106 & 104 & & $100 \%$ & $0.62[0.25,1.55]$ \\
\hline \multicolumn{6}{|c|}{ Total events: 7 (Early planned removal), 11 (Expectant management) } \\
\hline \multicolumn{6}{|c|}{ Test for overall effect: $Z=1.02(P=0.31)$} \\
\hline & & urs early removal & $0.50 .7 \quad 1$ & irs expectan & \\
\hline
\end{tabular}

\section{APPENDICES}

\section{Appendix 1. Electronic searches}

Database: Epub Ahead of Print, In-Process \& Other Non-Indexed Citations, Ovid MEDLINE(R) Daily and Ovid MEDLINE(R) $<1946$ to Present>

\section{Search date $=11$ May 2017}

1 exp Infant, Newborn/ (561659)

2 Premature Birth/ (10046)

3 (neonat\$ or neo nat\$).ti,ab. (231996)

4 (newborn\$ or new born\$ or newly born\$).ti,ab. (150691)

5 (preterm or preterms or pre term or pre terms).ti,ab. (61041)

6 (preemie\$ or premie or premies).ti,ab. (142)

7 (prematur\$ adj3 (birth\$ or born or deliver\$)).ti,ab. (13998)

8 (low adj3 (birthweight\$ or birth weight\$)).ti,ab. (30648)

9 (lbw or vlbw or elbw).ti,ab. (7095)

10 infan\$.ti,ab. (388884)

11 (baby or babies).ti,ab. (62184)

121 or 2 or 3 or 4 or 5 or 6 or 7 or 8 or 9 or 10 or 11 (954982)

13 exp Catheterization, Central Venous/ (13775) 
14 catheters/ or catheters, indwelling/ or central venous catheters/ (22236)

15 (central adj3 line\$).ti,ab. (4845)

16 peripherally-inserted.ti,ab. (1191)

17 CVC.ti,ab. (3421)

18 CVL.ti,ab. (723)

19 PCVC.ti,ab. (29)

20 PICC.ti,ab. (818)

21 Umbilical Veins/ (12484)

22 UVC.ti,ab. (1531)

23 UAC.ti,ab. (326)

24 (umbilical adj3 cathet\$).ti,ab. (1353)

25 (umbilical adj3 cannul\$).ti,ab. (68)

26 (umbilical adj3 line\$).ti,ab. (303)

27 Broviac.ti,ab. (345)

28 Hickman.ti,ab. (868)

2913 or 14 or 15 or 16 or 17 or 18 or 19 or 20 or 21 or 22 or 23 or 24 or 25 or 26 or 27 or $28(53640)$

3012 and $29(5826)$

31 randomized controlled trial.pt. (462319)

32 controlled clinical trial.pt. (94052)

33 randomized.ab. (403854)

34 placebo.ab. (188944)

35 drug therapy.fs. (1992401)

36 randomly.ab. (280501)

37 trial.ab. (422891)

38 groups.ab. (1728008)

3931 or 32 or 33 or 34 or 35 or 36 or 37 or $38(4102646)$

40 exp animals/ not humans.sh. (4397724)

4139 not $40(3547814)$

4230 and $41(1083)$

\section{Database:Embase <1974 to 2017 May 10>}

\section{Search date $=11$ May 2017}

1 newborn/ (517554)

2 prematurity/ (86628) 
3 (neonat\$ or neo nat\$).ti,ab. (287899)

4 (newborn\$ or new born\$ or newly born\$).ti,ab. (177117)

5 (preterm or preterms or pre term or pre terms).ti,ab. (80444)

6 (preemie\$ or premie or premies).ti,ab. (203)

7 (prematur\$ adj3 (birth\$ or born or deliver\$)).ti,ab. (17967)

8 (low adj3 (birthweight\$ or birth weight\$)).ti,ab. (36575)

9 (lbw or vlbw or elbw).ti,ab. (9138)

10 infan\$.ti,ab. (439127)

11 (baby or babies).ti,ab. (81178)

121 or 2 or 3 or 4 or 5 or 6 or 7 or 8 or 9 or 10 or $11(1036635)$

13 exp central venous catheterization/ (8081)

14 catheter/ (49569)

15 exp indwelling catheter/ (12385)

16 exp central venous catheter/ or hickman catheter/ or peripherally inserted central venous catheter/ or subclavian vein catheter/ (18067)

17 (central adj3 line\$).ti,ab. (7592)

18 peripherally-inserted.ti,ab. (1889)

19 CVC.ti,ab. (5399)

20 CVL.ti,ab. (1020)

21 PCVC.ti,ab. (45)

22 PICC.ti,ab. (1828)

23 umbilical vein/ (13825)

24 UVC.ti,ab. (1816)

25 UAC.ti,ab. (435)

26 (umbilical adj3 cathet\$).ti,ab. (1708)

27 (umbilical adj3 cannul\$).ti,ab. (89)

28 (umbilical adj3 line\$).ti,ab. (422)

29 Broviac.ti,ab. (395)

30 Hickman.ti,ab. (1038)

3113 or 14 or 15 or 16 or 17 or 18 or 19 or 20 or 21 or 22 or 23 or 24 or 25 or 26 or 27 or 28 or 29 or 30 (106884)

3212 and $31(8504)$

33 clinical trial/ (920773)

34 randomized controlled trial/ (445616)

35 randomization/ (73342)

36 single blind procedure/ (26575)

37 double blind procedure/ (137474)

Early planned removal of umbilical venous catheters to prevent infection in newborn infants (Review) 
38 crossover procedure/ (50870)

39 placebo/ (304347)

40 randomi?ed controlled trial\$.tw. (155509)

41 rct.tw. (23732)

42 random allocation.tw. (1668)

43 randomly allocated.tw. (27182)

44 allocated randomly.tw. (2236)

45 (allocated adj2 random).tw. (861)

46 single blind\$.tw. (19159)

47 double blind\$.tw. (177157)

48 ((treble or triple) adj blind\$).tw. (684)

49 placebo\$.tw. (252743)

50 prospective study/ (370954)

5133 or 34 or 35 or 36 or 37 or 38 or 39 or 40 or 41 or 42 or 43 or 44 or 45 or 46 or 47 or 48 or 49 or 50 (1733765)

52 case study/ (46451)

53 case report.tw. (335270)

54 abstract report/ or letter/ (1012042)

5552 or 53 or 54 (1386028)

5651 not $55(1688954)$

5732 and $56(857)$

Database:Maternity \& Infant Care Database (MIDIRS) via OVID <1971 to March 2017>

\section{Search date $=11$ May 2017}

1 (neonat\$ or neo nat\$).ti,ab. (37541)

2 (newborn\$ or new born\$ or newly born\$).ti,ab. (17281)

3 (preterm or preterms or pre term or pre terms).ti,ab. (21945)

4 (preemie\$ or premie or premies).ti,ab. (48)

5 (prematur\$ adj3 (birth\$ or born or deliver\$)).ti,ab. (3526)

6 (low adj3 (birthweight\$ or birth weight\$)).ti,ab. (9603)

7 (lbw or vlbw or elbw).ti,ab. (2624)

8 infan\$.ti,ab. (55675)

9 (baby or babies).ti,ab. (26173)

101 or 2 or 3 or 4 or 5 or 6 or 7 or 8 or 9 (103259)

11 Catheterization.de. (1)

Early planned removal of umbilical venous catheters to prevent infection in newborn infants (Review) 
12 Catheters.de. (2)

13 catheter $\$ . t i, a b . ~(1659)$

14 (central adj3 line\$).ti,ab. (150)

15 catheter\$.ti,ab. (1659)

16 peripherally-inserted.ti,ab. (82)

17 CVC.ti,ab. (36)

18 CVL.ti,ab. (5)

19 PCVC.ti,ab. (10)

20 PICC.ti,ab. (46)

21 Umbilical veins.de. (65)

22 UVC.ti,ab. (24)

23 UAC.ti,ab. (19)

24 (umbilical adj3 cathet\$).ti,ab. (186)

25 (umbilical adj3 cannul\$).ti,ab. (2)

26 (umbilical adj3 line\$).ti,ab. (25)

27 Broviac.ti,ab. (2)

28 Hickman.ti,ab. (3)

2911 or 12 or 14 or 15 or 16 or 17 or 18 or 19 or 20 or 21 or 22 or 23 or 24 or 25 or 26 or 27 or 28 (1823)

3010 and $29(1049)$

31 limit 30 to randomised controlled trial (53)

\section{Database:CENTRAL via John Wiley's Cochrane Library Interface}

Search Name: central lines Infants 11052017

\section{Records retrieved $=\mathbf{3 7 2}$}

\section{IDSearch}

\#1 MeSH descriptor: [Infant, Newborn] explode all trees

\#2 MeSH descriptor: [Premature Birth] explode all trees

\#3 neonat*:ti,ab,kw (Word variations have been searched)

\#4 neo-nat*:ti,ab,kw (Word variations have been searched)

\#5 newborn or new born* or newly born*:ti,ab,kw (Word variations have been searched)

\#6 preterm or preterms or (pre term) or (pre terms):ti,ab,kw (Word variations have been searched)

\#7 preemie* or premie or premies:ti,ab,kw (Word variations have been searched)

\#8 prematur ${ }^{\star}$ near/3 (birth* or born or deliver $\left.{ }^{\star}\right): t i, a b, k w$ (Word variations have been searched)

\#9 low near/3 (birthweight* or birth weight $\left.{ }^{\star}\right): t i, a b, k w$ (Word variations have been searched)

\#10 lbw or vlbw or elbw:ti,ab,kw (Word variations have been searched)

Early planned removal of umbilical venous catheters to prevent infection in newborn infants (Review) 
\#11 infan* or baby or babies:ti,ab,kw (Word variations have been searched)

$\# 12 \# 1$ or \#2 or \#3 or \#4 or \#5 or \#6 or \#7 or \#8 or \#9 or \#10 or \#11

\#13 MeSH descriptor: [Catheterization, Central Venous] explode all trees

\#14 MeSH descriptor: [Catheters] explode all trees

\#15 MeSH descriptor: [Catheters, Indwelling] explode all trees

\#16 MeSH descriptor: [Central Venous Catheters] explode all trees

\#17 central near/3 line*:ti,ab,kw (Word variations have been searched)

\#18 peripherally-inserted:ti,ab,kw (Word variations have been searched)

\#19 CVC or CVL or PCVC or PICC:ti,ab,kw (Word variations have been searched)

\#20 MeSH descriptor: [Umbilical Veins] explode all trees

\#21 UVC or UAC:ti,ab,kw (Word variations have been searched)

\#22 (umbilical near/3 (cathet* or cannul* or line $\left.{ }^{\star}\right)$ ):ti,ab,kw (Word variations have been searched)

\#23 Broviac or hickman:ti,ab,kw (Word variations have been searched)

$\# 24 \# 13$ or \#14 or \#15 or \#16 or \#17 or \#18 or \#19 or \#20 or \#21 or \#22 or \#23

$\# 25 \# 12$ and \#24

\section{Trials registers searches}

ClinicalTrials.gov

https://clinicaltrials.gov/ct2/home

11 May 2017

147 studies found for: catheter AND infant

WHO ICTRP

http://apps.who.int/trialsearch/Default.aspx

11 May 2017

((central line $\left.{ }^{\star}\right)$ OR catheter $\left.{ }^{\star}\right)$ AND infant ${ }^{\star} 10$ records

\section{Appendix 2. Risk of bias}

- Random sequence generation: We categorised the method used to generate the allocation sequence as:

- Low risk of bias: any random process (e.g. random number table; computer random number generator; coin tossing; shuffling of cards or envelopes; throwing of dice; drawing of lots; minimization) implemented without a random element (this is considered equivalent to being random);

- High risk of bias: any non-random process (e.g. sequence generated by odd or even date of birth; date (or day) of admission; sequence generated by hospital or clinic record number; allocation by judgement of the clinician; allocation by preference of the participant; allocation based on results of a laboratory test or series of tests; allocation based on availability of the intervention); or

- Unclear risk of bias: insufficient information about the sequence generation process to permit judgement.

- Allocation concealment: We categorised the method used to conceal the allocation sequence as:

- Low risk of bias: randomisation method described that would not allow investigator/participant to know or influence the intervention group before eligible participants entered the study (i.e. central allocation, including telephone, Web-based, and pharmacy-controlled randomisation; sequentially numbered drug containers of identical appearance; sequentially numbered opaque, sealed envelopes); 
- High risk of bias: open random allocation schedule (i.e. list of random numbers); assignment envelopes used without appropriate safeguards (e.g. envelopes were unsealed or non-opaque, were not sequentially numbered); alternation or rotation; date of birth; case record number; any other explicitly unconcealed procedure; or

- Unclear risk of bias: randomisation stated but no information provided on method used.

- Blinding of participants and personnel: We assessed blinding of participants, clinicians and caregivers, and outcome assessors separately for different outcomes and categorised methods as:

- Low risk of bias: no blinding or incomplete blinding, but review authors judged that the outcome was not likely to be influenced by lack of blinding; blinding of participants and key study personnel ensured, and unlikely that blinding could have been broken;

- High risk of bias: no blinding or incomplete blinding, and outcome was likely to be influenced by lack of blinding; blinding of key study participants and personnel attempted, but likely that blinding could have been broken, and the outcome was likely to be influenced by lack of blinding; or

- Unclear risk of bias: insufficient information to permit judgement.

- Incomplete outcome data: We described completeness of data including attrition and exclusions from the analysis for each outcome and reasons for attrition or exclusion when reported. We assessed whether missing data were balanced across groups or were related to outcomes. We categorised completeness as:

- Low risk of bias: no missing outcome data; reasons for missing outcome data unlikely to be related to true outcome (for survival data, censoring unlikely to introduce bias); missing outcome data balanced in numbers across intervention groups, with similar reasons for missing data across groups; for dichotomous outcome data, proportion of missing outcomes compared with observed event risk not enough to have a clinically relevant impact on the intervention effect estimate; for continuous outcome data, plausible effect size (difference in means or standardised difference in means) among missing outcomes not sufficient to have a clinically relevant impact on observed effect size; missing data imputed by appropriate methods;

- High risk of bias: reason for missing outcome data likely to be related to true outcome, with imbalance in numbers or reasons for missing data across intervention groups; for dichotomous outcome data, proportion of missing outcomes compared with observed event risk enough to induce clinically relevant bias in intervention effect estimate; for continuous outcome data, plausible effect size (difference in means or standardised difference in means) among missing outcomes enough to induce clinically relevant bias in observed effect; 'as-treated' analysis done with substantial departure of the intervention received from that assigned at randomisation; potentially inappropriate application of simple imputation; or

- Unclear risk of bias: insufficient information to permit judgement.

\section{Appendix 3. GRADE}

GRADE considers that evidence from randomised controlled trials is of "high" quality, but that assessment may be downgraded based on consideration of any of five areas.

- Design (risk of bias) (Guyatt 2011b).

- Consistency across studies (Guyatt 2011c).

- Precision of estimates (Guyatt 2011d).

- Directness of evidence (Guyatt 2011e).

- Presence of publication bias.

This results in assessment of the quality of a body of evidence as one of four grades.

1. High: We are very confident that the true effect lies close to that of the estimate of the effect.

2. Moderate: We are moderately confident in the effect estimate: The true effect is likely to be close to the estimate of the effect, but there is a possibility that it is substantially different.

3. Low: Our confidence in the effect estimate is limited: The true effect may be substantially different from the estimate of the effect.

4. Very low: We have very little confidence in the effect estimate: The true effect is likely to be substantially different from the estimate of effect.

\section{CONTRIBUTIONSOF AUTHORS}

MG and WM wrote the review. AG revised and edited the review.

\section{DECLARATIONSOF INTEREST}

None of the review authors reports a potential conflict of interest. 


\section{SOURCES OF SUPPORT}

\section{Internal sources}

- Royal Prince Alfred Hospital, Sydney, Australia.

Literature search

- University of York, UK.

\section{External sources}

- National Institute for Health Research, UK.

This report is independent research funded by a UK National Institute of Health Research Grant (NIHR) Cochrane Programme Grant (13/89/12). The views expressed in this publication are those of the authors and not necessarily those of the NHS, the NIHR, or the UK Department of Health.

- Eunice Kennedy Shriver National Institute of Child Health and Human Development, National Institutes of Health, Department of Health and Human Services, USA.

Editorial support of the Cochrane Neonatal Review Group has been funded with Federal funds from the Eunice Kennedy Shriver National Institute of Child Health and Human Development, National Institutes of Health, Department of Health and Human Services, USA, under Contract No. HHSN275201600005C.

\section{DIFFERENCES BETWEEN PROTOCOLAND REVIEW}

None.

\section{IN DEX TERMS}

\section{Medical Subject Headings (MeSH)}

*Device Removal; *Infant, Very Low Birth Weight; *Umbilical Veins; Catheter-Related Infections [epidemiology] [ ${ }^{*}$ prevention \& control]; Catheterization, Peripheral; Catheters [ ${ }^{*}$ adverse effects]; Cause of Death; Central Venous Catheters; Thrombosis [etiology]; Time Factors

\section{MeSH check words}

Humans; Infant, Newborn 